\title{
Establishing an ecological security pattern for urban agglomeration, taking ecosystem services and human interference factors into consideration
}

\author{
Dongchuan Wang ${ }^{\text {Corresp., } 1,2}{ }^{2}$, Junhe Chen ${ }^{1}$, Lihui Zhang ${ }^{1}$, Zhichao Sun ${ }^{1}$, Xiao Wang ${ }^{1}$, Xian Zhang ${ }^{1}$, Wei Zhang ${ }^{1}$ \\ ${ }^{1}$ School of Geology and Geomatics, Tianjin Chengjian University, Tianjin, China \\ 2 Tianjin Key Laboratory of Civil Structure Protection and Reinforcement, Tianjin, China \\ Corresponding Author: Dongchuan Wang \\ Email address: mrwangdc@126.com
}

The assessment of ecological security patterns is a topic of conversation in landscape ecology in recent years. However, ecosystem services and human activities are seldom considered comprehensively in the assessment of ecological security patterns. The present study employs the Beijing-Tianjin-Hebei urban agglomeration as a study area, and uses ecological services to determine the ecological sources, The importance of ecological sources is classified based on logical coding and functional types of ecological services, the research combines regional characteristicsto select and quantitatively calculate three human disturbance factors:soil erosion sensitivity, geological hazard sensitivity, and night lighting. Then the basic resistance surface of land use to limit migration is modified and ecological corridors are identified by combining these three disturbance factors. The results indicate that the sources of water production, soil and water conservation, and carbon fixation are mainly provided in mountainous areas, recreation sources are mostly distributed in the plains, and these ecological sources improve the maintenance of ecological corridors. The modification of resistance surfaces significantly changes the length of ecological corridors in Tianjin, Tangshan, Cangzhou, and Beijing, and the modified resistance surface improves the recognition of ecological corridors. This study provides a new research framework for identifying the ecological security patterns of urban agglomerations and provides scientific guidance related to ecological protection and urban planning for the Beijing-Tianjin-Hebei urban agglomeration. 
1 Establishing an ecological security pattern for urban agglomeration, taking ecosystem services and human interference factors into consideration

3 Dongchuan Wang1, 2, Junhe Chen', Lihui Zhang1, Zhichao Sun ${ }^{1}$, Xiao Wang ${ }^{1}$, Xian Zhang1,

4 Wei Zhang ${ }^{1}$

$5 \quad{ }^{1}$ School of Geology and Geomatics, Tianjin Chengjian University, Tianjin, China

$6{ }^{2}$ Tianjin Key Laboratory of Civil Structure Protection and Reinforcement, Tianjin, China

7 Corresponding Author:

8 Dongchuan Wang ${ }^{1,2}$

9 No. 26 Jinjing RD, Xiqing District, Tianjin, 300384, China

10 Email address: mrwangdc@126.com

Abstract

The assessment of ecological security patterns is a topic of conversation in landscape ecology in recent years. However, ecosystem services and human activities are seldom considered comprehensively in the assessment of ecological security patterns. The present study employs the Beijing-Tianjin-Hebei urban agglomeration as a study area, and uses ecological services to determine the ecological sources, The importance of ecological sources is classified based on logical coding and functional types of ecological services, the research combines regional characteristics to select and quantitatively calculate three human disturbance factors: soil erosion sensitivity, geological hazard sensitivity, and night lighting. Then the basic resistance surface of land use to limit migration is modified and ecological corridors are identified by combining these three disturbance factors. The results indicate that the sources of water production, soil and water conservation, and carbon fixation are mainly provided in mountainous areas, recreation sources are mostly distributed in the plains, and these ecological sources improve the maintenance of ecological corridors. The modification of resistance surfaces significantly changes the length of ecological corridors in Tianjin, Tangshan, Cangzhou, and Beijing, and the modified resistance surface improves the recognition of ecological corridors. This study provides a new research framework for identifying the ecological security patterns of urban agglomerations and provides scientific guidance related to ecological protection and urban planning for the Beijing-TianjinHebei urban agglomeration.

\section{Introduction}

While urbanization provides beneficial results to modern civilization, it also creates a series of ecological and environmental problems, such as the loss of natural landscapes, a decline in ecosystem services, and the aggravation of environmental health risks, which can affect the sustainable development of cities (Han et al., 2015). Therefore, ensuring the stability and functioning of urban ecosystems while promoting sustainable urban development has become a 
major issue facing the international community (Cumming et al., 2017).

In general, the goal of establishing an ecological security pattern is to achieve regional ecological sustainability through integrating landscape patterns with ecological processes while comparing the importance of different landscape patches to specific ecological processes and ecosystem services (Peng et al., 2018). Documenting ecological security patterns can restrict the expansion of urbanization, regulate ecological processes reasonably, maintain material and energy cycles, strengthen urban ecological health, and promote sustainable urban development (Li et al., 2011).

Since the 1990s, many scholars have conducted extensive research on the development of ecological security patterns, including theoretical exploration, index development, and method realization, they have achieved a series of important results (Ahern, 1995; Zube, 1995; Albanese et al., 2016; Miao et al., 2015). The scope of ecological security pattern research includes species conservation (Dalang et al., 2012), land management (Gaaff et al., 2012), urban planning (Dong et al., 2015), and habitat protection (Kang et al., 2016). The assessment of ecological security patterns is a topic of conversation in landscape ecology in recent years. However, ecosystem services and human activities are seldom considered comprehensively in the assessment of ecological security patterns (Peng et al., 2018; Zhang et al., 2017; Jing et al., 2018; Dong et al., 2015). Currently, the development of ecological security patterns utilizing ecosystem supply needs has formed a research paradigm including the identification of ecological sources, and ecological corridors (Klar et al., 2012; Gu et al., 2016; Yang et al., 2018). The first step in ecological security pattern development is to identify ecological sources, mainly combining large-scale habitat patches, nature reserves and scenic spots to directly select the ecological source (Teng et al., 2011; Gurrutxaga et al., 2010), or through ecological sensitivity, ecological importance, landscape connectivity and evaluation of ecological suitability (Su et al.,2016; Kong et al., 2010; zhang et al., 2016). Ecological sources are the areas that provide the individuals involved in species dispersal, maintenance, and landscape components to promote the development of ecological processes (Chen et al., 2008). Ecological sources are identified by quantitative assessment of regional ecological security patterns (Wu et al., 2013). Ecosystem services refers to the environmental conditions and effects on which human beings depend for survival and development. These services include not only food, fresh water, and raw materials for industrial and agricultural production provided by ecosystems but more importantly, these services support and maintain of ecosystems (Daily, 1997). Therefore, it is of great significance to identify the areas that provide the highest level of ecological service as the ecological source areas for maintaining urban ecological security (Peng et al., 2018). However, most of the current research identified ecological source areas by considering the function of ecological services, they did not consider the effects of different types of ecological services on the importance of the same ecological source. The definition and functional classification of ecological sources is not only the basis for the formulation of relevant ecological policies, but also the former must be clear for urban development and construction. The problem is related to the rational use of land resources and the sustainable development of human society (Egoh et al., 2008). In recent years, most studies have shown that clarifying the impact of ecological service categories on the importance of the ecological source areas is helpful in understanding the corresponding relationship between ecological source areas and ecological service functions. Moreover understanding the relationships among multiple ecosystem services and the mechanisms behind these relationships will improve our ability to sustainably manage landscapes in order to provide multiple ecosystem services (Bennett et al., 2009) towards an integrated ecological sources 
management (Raudsepp-Hearne et al., 2010; Kareiva et al., 2007).

The next step in ecological security pattern development is to identify ecological corridors. In the extraction of ecological corridors, the most commonly used method is the GIS-based modeling approach proposed by Knaapen (1992) and improved by Yu (1999) based on the minimum cumulative resistance model. GIS is a comprehensive technology for processing geospatial information. It can not only express visible spatial positional relationships, but also reflect spatial locations or related numerical values, words and charts that reflect the characteristics of things (Beni et al., 2011). Urban ecological planning is necessary to accurately judge and decide the spatial layout relationship between urban ecological environment and urban development and construction, and as a complex and comprehensive research field, it needs the abstract data of various spatial information to be processed (Aretano et al., 2015). GIS as a decision support tool for environmental protection and nature reserve protection can play a targeted role in spatial relationship processing and data analysis. The GIS-based modeling approach has been used for numbers of urban planning applications in China ( $\mathrm{Su}$ et al., 2016; Dong et al., 2015), where resistance is the degree of impediment to species migration between landscape units. Currently, the development of resistance surfaces is generally based on developing a resistance coefficient related to ecological factors such as land cover type and slope (Fu et al., 2010). The method does not consider the spatial differences caused by specific ecological problems in different regions. The correction of the resistance surface is also based on nighttime lighting (Zhang et al., 2017) or imperious index data (Peng et al., 2018) that are used to enhance the spatial differences in resistance surfaces. The method considers the spatial differences caused by specific ecological problems in resistance surfaces, but is generally based on the qualitative evaluation of ecological security patterns for a single problem, the extent of the spatial coverage is generally aimed at the province (Peng et al., 2018), city (Li et al., 2010), or county level (Yu et al., 2018). As a relatively complex ecosystem, an urban agglomeration involved various aspects of ecological security, each of which included many factors influencing urban conditions. A comprehensive evaluation cannot be done by studying ecological security based on a single factor (Chen et al., 2018).

The health and sustainable development of the Beijing-Tianjin-Hebei urban agglomeration is important ensurancing of china's national security. However, human activities become more frequent with intense urbanization, which leads to a series of ecological problems (Gong et al., 2009; Liu et al., 2017; Duan et al.,2015). Among them, soil and water conservation serve as an important ecological safeguards in support of economic and social development these should play an important role in the coordinated development of the Beijing-Tianjin-Hebei region (Chen et al., 2017; Miao et al., 2011). In addition, the fragile ecological base, changing climatic conditions, and intense activity frequently cause geological disasters in the Beijing-TianjinHebei urban agglomeration (Meng et al.,2017). Soil erosion and geological hazard sensitivity indices reflect the degree of ecosystem response to human disturbance and natural environment changes (Ou Yang et al., 2000). Night light data are widely used in the study of population density, economic development, and urban heat island effects, etc. This spatial measures indicators are a comprehensive characterization of the intensity of human activity in an area (Mellander et al., 2015). In areas that are highly sensitive to soil erosion and geological hazards, that have nighttime light, the intensity of human activity is normally relatively high, which has a certain effect on regional the migration of urban species. Therefore, with setting the BeijingTianjin-Hebei urban agglomeration as the study area, this study employs an analysis of ecosystem services and human disturbance factors to construct ecological security patterns, with 
the goal of reducing the negative effects of human activities on the ecological security pattern of the Beijing-Tianjin-Hebei urban agglomeration. Hence, the research objectives were proposed as follows: (1) One objective was to determine the ecological source of various resources through a quantitative evaluation of water production services, soil and water conservation, carbon fixation services, as well as leisure and recreation services. (2) To determine the importance of dividing ecological sources by combining logical coding and ecological service function types. Finally, (3) using the soil erosion sensitivity, geological hazard sensitivity, and nighttime light indices, we wanted to modify ecological resistance surfaces based on land use to identify ecological corridors.

\section{Methodology}

Ecological security patterns combine landscape pattern with ecological processes to achieve regional ecological sustainability by comparing the importance of different landscape patterns (Peng et al., 2018). The ecological security pattern of the Beijing-Tianjin-Hebei urban agglomeration constructed in this study consists of four steps: firstly, ecological services are used to determine the ecological sources. Second, the importance of the ecological sources is determined by combining the logical coding and identification of the type of ecological services. Thirdly, the basic resistance surface is modified with human interference factors. Finally, the ecological corridor is extracted by using the minimum cumulative resistance model. The flow chart of this study is shown in Figure 1.

Figure 1: Overview of the construction of ecological security patterns.

\subsection{Study area and data sources}

The Beijing-Tianjin-Hebei urban agglomeration lies in the coastal area of Eastern China, and covers a total area of $218,000 \mathrm{~km}^{2}$. In this region, the Yanshan Mountains delimit the north, the North China Plain lies to the south, the Taihang Mountains stand to the west, and the Bohai Sea borders the eastern edge of the region (Figure 2). The cold and snowy climate in winter gives way to an arid spring with high wind speeds and frequent sandstorms, summers are hot and rainy, which is conducive to rock and soil weathering. According to a survey, by 2015, a total of 7255 geological hazards and hidden dangers were found in the study area, including 3526 collapses, 770 landslides, 2288 debris flows and 671 ground collapses (Meng et al.,2017). The human population accounts for $7.8 \%$ of the total population of China, making this urban agglomeration a densely populated area. Data preprocessing and data processing are mainly done with GIS tools. The data sources are shown in Table 1.

Figure 2: Location of the Beijing-Tianjin-Hebei urban agglomeration and Digital Elevation Model (DEM) of the study area.

Table 1: Data sources 


\subsection{Ecological sources}

\subsubsection{Ecological service function assessment}

Assessment of the importance of ecosystem services frequently serves as a basic method used to identify regional sources of ecological services. This is done by analyzing variation in regional ecological services and identifying the areas that are most important for the maintenance of typical regional ecosystems. Therefore, the present study quantitatively identifies and evaluates services of water production, water and soil conservation, carbon fixation, and those related to leisure and recreation of the urban agglomeration in combination with an analysis of the characteristics of the natural environment of the Beijing-Tianjin-Hebei urban agglomeration.

In particular, the function of water production is based on the water cycle. Water production depends on the rainfall in a grid unit minus the actual evapotranspiration (Miao et al., 2010). In the present study, the Integrated Valuation of Ecosystem Services and Trade-offs water yield assessment model was used to evaluate the ecological service functions in this region. The Integrated Valuation of Ecosystem Services and Trade-offs model is a tool used for the comprehensive assessment and balancing of ecosystem services developed jointly by Stanford University, the Worldwide Fund for Nature , and the Nature Conservancy.

The revised universal soil loss equation model was used to evaluate soil and water conservation in the studied region. The universal soil loss equation (USLE) model, namely the general soil loss equation, was originally established by Wischmeier and Smith (1965) based on a large amount of plot observation and simulated rainfall experimental data. In 1992, The United States Department of Agriculture-Agricultural Research Service improved the USLE model and initially proposed the revised USLE model for soil erosion analysis. The formula is provided in Eq. (1):

$$
A_{c}=A_{p}-A_{r}=R \times K \times L \times S \times(1-C) .
$$

where $A_{c}$ is the amount of soil and water conservation, $\mathrm{t} /\left(\mathrm{hm} \mathrm{m}^{2} \cdot \mathrm{a}\right) ; A_{p}$ is the potential amount of soil erosion; $A_{r}$ is the actual amount of soil erosion; $\mathrm{R}$ is the factor of rainfall erosivity, $\mathrm{MJ} \cdot \mathrm{mm} /\left(\mathrm{hm}^{2} \cdot \mathrm{h} \cdot \mathrm{a}\right) ; \mathrm{K}$ is the factor of soil erodibility, $\mathrm{t} \cdot \mathrm{h} \mathrm{m}^{2} \cdot h /\left(h \mathrm{~m}^{2} \cdot \mathrm{MJ} \cdot \mathrm{mm}\right)$; $\mathrm{L}$ and $\mathrm{S}$ are the topographic factors; L are the factor of slope length. $\mathrm{S}$ is the slope factor, and $\mathrm{C}$ is vegetation cover management factor.

The service of carbon fixation was evaluated basing on the principle of light energy utilization. The estimation formula is shown in Eq. (2):

$$
\mathrm{NPP}=\mathrm{PAR} \times \mathrm{FPAR} \times \varepsilon^{*} \times \mathrm{f}(\mathrm{w}) \times \mathrm{f}(\mathrm{t})-\mathrm{R}_{a}
$$

Where PAR is photosynthetically active radiation, the unit is $M J / m^{2}$; FPAR is the absorption component of the vegetation layer to the incident photosynthetically active radiation, no unit; $\varepsilon^{*}$ is the maximum light energy utilization rate, the unit is $\mathrm{gC} / \mathrm{MJ}$; $\mathrm{f}(\mathrm{t})$ is the influence factor of temperature on the utilization of light energy, no unit; $f(w)$ is the influence factor of water on the utilization of light energy, no unit; $R_{a}$ is the autotrophic respiration of vegetation, the unit is $g C / \mathrm{m}^{2}$.

The leisure and recreation service mainly considers the wetlands of the Beijing-TianjinHebei urban agglomeration. Buffer zones of pedestrian walking distance to these wetlands of 5 , $10,15,20$, and 25 minutes (min) were analyzed, which are included in different levels of leisure 
207

208

209

210

211

212

213

214

215

216

217

218

219

220

221

222

223

224

225

226

227

228

229

230

231

232

233

234

235

236

237

238

239

240

241

242

243

244

245

246

247

and recreation, aiming at emphasizing the effects of human activities (Peng et al., 2018).

\subsubsection{Ecological source level}

Based on quantitatively evaluating the ecosystem services of the studied region and identifying the ecological source areas, logical coding is introduced to identify the ecosystem services of different ecological sources. This coding is used to represent one or more types of ecocystem services contained in the ecological source area. The logical coding in this study uses "1"or " 0 " to indicate that a grid has or does not have a particular ecosystem service, respectively. In the present study, the raster computing function of ArcGIS ver. 10.2 was combined to obtain the spatial pattern of the logical coding of each ecological service category. Equation (3) provides the logical coding system:

$$
T_{i j}=(G 1)_{i j} \times 10^{n-1}+(G 2)_{i j} \times 10^{n-2}+\ldots+(G n)_{i j} \times 10^{n-n}
$$

in which $\mathrm{T}$ is the logical coding value of column $\mathrm{j}$ and row $\mathrm{i}$ in the raster image of logical analysis results, which indicates one or more ecosystem service categories, and $n$ is the number of ecosystem services. The present study looked at four ecosystem services. Therefore, $\mathrm{n}=4$ and $G 1_{i j}, G 2_{i j}, G 3_{i j}$ and $G 4_{i j}$ are the logical coding of the corresponding raster types on the raster images of the services of water production, water and soil conservation, carbon fixation, and leisure with recreation, respectively. For example, if the type logical coding is "1101", it means that the ecological source area has the services of water production, water and soil conservation and leisure, and does not have the service of carbon fixation.

In the present study, the ecological source areas were classified as described above based on the logical coding to determine the importance of each ecological source area. If three or four of the ecological services are coded using the number " 1 ", the area is determined to be a primary ecological source; if only two or one are coded using the number of "1", the area is determined to be a secondary or tertiary ecological source.

\subsection{Resistance surface}

The concept of an ecological resistance surface refers to the degree of impediment to species migration between landscape units. The spatial differences of specific ecological problems in small-scale areas can often be solved by constructing desirable ecological resistance surface based on the single-factor correction of land cover types. However, as a relatively large urban agglomeration, land managers of the Beijing-Tianjin-Hebei region should not only consider the ecological problems confined to specific areas, but should also analyze the region as a whole. Geological conditions in the Beijing-Tianjin-Hebei urban agglomeration are complex and fragile, landslides, debris flows, and serious soil erosion occur frequently in the region. Increasingly human activities interfere with the natural landscape conditions, this is especially true as it relates to the expansion of urbanization. These factors will have a great impact on species migration and regional ecological security and stability. Therefore, in this study, sensitivity indices tied to geological hazards, soil erosion, and night light data are introduced to modify the basic ecological resistance surface based on land use. In addition, the ecological red line corridors were manually vectorized in the Beijing, Tianjin, and Hebei Red Lines of Ecological Protection in 2018. Initially, ecological resistance is assigned to 0 and finally superimposed on the basic resistance surface, then the revised resistance surface is converted into

Peer] reviewing PDF | (2019:03:35477:2:1:NEW 13 Jun 2019) 
248

249

250

251

252

253

254

255

256

257

258

259

260

261

262

263

264

265

266

267

268

269

270

271

272

273

274

275

276

277

278

279

280

281

282

283

284

285

286

287

288

raster format. Among, the above three sensitivity indices, that of soil erosion adopts the evaluation indexes of precipitation erosivity, soil erodibility, slope length and surface vegetation cover, which have been proposed based on the red line technical guidelines for ecological protection of Yang et al. (2016). The sensitivity index of geological hazards used nine indicators to calculate the total distribution weight of the layers (Table 2). The weight of each index was determined by Analytic Hierarchy Process (A.H.P) (Saaty, 1987). The analytic hierarchy process is completed by Yaahp software, which is a comprehensive evaluation assistant software based on the analytic hierarchy process and fuzzy comprehensive evaluation method. The consistency test of the results of the A.H.P is carried out where the Consistency Index (C.I) value is 0.1056, because the calculation of geological hazard sensitivity includes 9 indicators, namely $n=9$, and the table is found, Random Index $(\mathrm{RI})=1.45$, Consistency Ratio $(\mathrm{CR})=0.0728<0.1$, indicating the judgment matrix has satisfactory consistency. In this paper, with the sensitivity analysis in Yaahp software, the number of sampling points is set to 100, and the corresponding total ranking weights when the middle layer elements change from 0 to 1 are calculated. The basic sensitivity indicators of disaster, terrain and other are $0.0423,0.0317$ and 0.0255 respectively. This indicator highlights the maximum range of weight change of each option caused by the change of the current element weight. Finally, the three factors were normalized and replaced by the specific ecological resistance surface correction as follows in Eq. (4):

$$
R_{i}=\left(w_{b} \times \frac{N L_{i}}{N L_{a}}+w_{c} \times \frac{S E_{i}}{S E_{a}}+w_{d} \times \frac{G S_{i}}{G S_{a}}\right) \times \mathrm{R}
$$

where $R_{i}$ is the ecological resistance coefficient of grid i based on the water loss sensitivity, night lighting, and geological hazard sensitivity indices, $N L_{i}$ is the night light of grid i, $N L_{a}$ is the average night light of the land use type a corresponding to grid i; $S E_{i}$ is the water and soil erosion sensitivity index of grid $\mathrm{i} ; S E_{a}$ is the average soil erosion sensitivity index of land use type a corresponding to grid i. $G S_{i}$ is the sensitivity index of geological hazards of grid i and $G S_{a}$ is the average geohazard sensitivity index of land use type a corresponding to grid $\mathrm{i}$, and $\mathrm{R}$ is the basic resistance coefficient of land use type corresponding to grid i. Since it is impossible to determine which factors have a greater impact on the resistance surface of an urban agglomeration, the weight of night lighting, soil and water loss sensitivity index and geological hazard sensitivity index is set to $1: 1: 1$, that is $w_{b}: w_{c}: w_{d}=1: 1: 1$.

Table 2: Weight of various factors of geological hazard sensitivity

\subsection{Ecological corridors}

Constructing ecological corridors can solve the problem of fragmentation related to ecological sources and enhance the connectivity among ecological sources. With the rapid development of the Beijing-Tianjin-Hebei urban agglomeration, the islanding and fragmentation of the local landscape has increased dramatically. The minimum cumulative resistance (MCR) model was first proposed by Knaapen (1992). This model considers three factors, source, distance, and landscape interface, to calculate the cost to a species caused by moving from a source to a destination, and it extracts the resistance trough between two adjacent "sources" and the most easily connected low-resistance channel as a corridor between ecological safe habitat sources as shown in Eq.(5): 
289

290

291

292

293

294

295

296

297

298

299

300

301

302

303

304

305

306

307

308

309

310

311

312

313

314

315

316

317

318

319

320

321

322

323

324

325

326

327

328

$\operatorname{MCR}=f_{\min } \sum_{j=n}^{i=m} D_{i j} \times R_{i}$.

where MCR is the minimum cumulative resistance value; $D_{i j}$ is the spatial distance of species from source $\mathrm{J}$ to landscape unit $\mathrm{i}, R_{i}$ is the resistance coefficient of landscape unit $\mathrm{i}$; and $\mathrm{f}$ is the positive correlation between minimum cumulative resistance and ecological process.

\section{Results}

\subsection{Spatial pattern of ecological sources}

\subsubsection{Spatial pattern of ecological services}

The spatial pattern of a single ecosystem services can reflect the effects of different ecological processes on regional ecological security. The assessment results of ecosystem services were divided into five levels from low to high by the natural breakpoint method as follows: generally, unimportant and slightly, moderately, highly and extremely important (Figure 3 ), at the same time, the area and area ratio occupied by important areas of various ecosystem service was calculated (Table 3).

Table 3: Area and proportion of different levels of ecosystem services

Figure 3: Spatial patterns of ecological services: Spatial patterns of (A) water production , (B) soil and water conservation,. (C) carbon fixation, (D) leisure and recreation services.

In the Beijing-Tianjin-Hebei urban agglomeration the water production service was generally higher in mountainous and hilly areas than that of plain and plateau areas, it is also higher in the western and eastern areas than in the central areas (Figure 3.A; Table 3). Most of the extremely important areas are located west of Handan and Xingtai, northwest of Baoding, and in a few scattered areas of the eastern coastal areas including Qinhuangdao, Tangshan, and Cangzhou. Most of these areas are located in the windward slopes of the Yanshan and Taihang Mountains that have a large amount of topographical relief and receive relatively higher amounts of precipitation, so the overall water production capacity is strong there. The total amount of the moderately and highly important areas for the water production service is not very different, the proportions of these areas were $8.37 \%$ and $8.26 \%$, respectively, and they were mainly distributed in the central plain area. Moreover, the spatial extent of generally important areas was the largest, accounted for $46.97 \%$, indicating that this urban agglomeration belongs to an area of serious water shortage.

In the Beijing-Tianjin-Hebei urban agglomeration the distribution of the soil and water conservation of area gradually devreased from the Yanshan and Taihang mountains to the surrounding areas (Figure 3.B; Table 3). The aforementioned area was the largest covering a total amount of $167,863.23 \mathrm{~km}^{2}$, accounting for $78.31 \%$ of the total study area. Except for extremely important areas, the proportion of other grades was not very different. The combined areas of the moderately, highly, and extremely important regions was $35,058.85 \mathrm{~km}^{2}$, accounting for only $16.36 \%$ of the total area, indicating that the overall soil and water conservation capacity of the region is relatively weak. As an important ecological area of soil and water conservation in

Peer] reviewing PDF | (2019:03:35477:2:1:NEW 13 Jun 2019) 
the Beijing-Tianjin-Hebei urban agglomeration, these areas are rich in precipitation, while the factors of soil erodibility are small, or the vegetation cover has a good ability to regulate and store precipitation; that is, these areas have a strong ability conserve water and soil.

In the Beijing-Tianjin-Hebei urban agglomeration the carbon fixation service is higher in the north and lower in the South and higher in the west and lower in the east (Figure 3.C; Table 3 ). The spatial differences among the important regions are relatively large. The areas of the highly and extremely important regions were $9691.46 \mathrm{~km}^{2}$, and $20,117.15 \mathrm{~km}^{2}$, respectively, with the area ratios of $4.48 \%$ and $9.31 \%$, respectively. They were mainly distributed in a small part of Handan, Xingtai, Shijiazhuang, Baoding, and Beijing and most of Chengde. Most of the land use types in these areas were forest, with abundant vegetation coverage, a humid climate, and good hydrothermal conditions, which can better meet plant growth requirements than other habitats. The area of moderately important areas covered 77,111.86 $\mathrm{km}^{2}$ which accounted for $35.67 \%$ of the study area. Most of moderately important areas were surrounded by highly and extremely important areas. The areas of generally and slightly important areas were 30,006.56 $\mathrm{km}^{2}$ and $79,240.88 \mathrm{~km}^{2}$ which accounted for $13.88 \%$ and $36.66 \%$ of the study area, respectively. These areas are basically developed but unused areas that are mainly distributed in the central, southern, and eastern parts of the region.

The leisure and recreational service of the Beijing-Tianjin-Hebei urban agglomeration presented a multi-point distribution pattern as a whole (Figure 3.D; Table 3). This service was mainly distributed in the plateau area of Zhangjiakou, the eastern area of Beijing, the southeastern area of Tianjin, and along the coastal area. The spatial extent of the most important area was $8701.79 \mathrm{~km}^{2}$, and it accounted for $4.03 \%$ of the entire area.

\subsubsection{Spatial pattern of the level of ecological sources}

The extremely important areas of each ecosystem service were selected as ecological source areas. The spatial pattern of the logical coding of the ecological service categories is shown in Figure 4. The area and proportion of logical coding of each ecosystem source type was also calculated (Table 4).

Figure 4: Spatial patterns of the ecological sources: Spatial patterns of the (A) logical coding of ecological service categories and (B) levels of ecological sources

Table 4: Area and proportion of logical coding of ecological service categories

The Beijing-Tianjin-Hebei urban agglomeration had eight types of ecological source areas (Figure 4.A; Table 4). The area of ecological sources covered $82,605.78 \mathrm{~km}^{2}$, accounting for $38.21 \%$ of the total area. Among them, the plain area provided the source of leisure and recreation services, and the source logical coding containing this function is 0001, accounting for $0.92 \%$ of the area of this urban agglomeration. Mountainous area is the source of water production, soil and water conservation and carbon fixation services. Among the four types of ecological sources, carbon fixation sources accounted for the largest proportion.

Most of the mountain areas are first or second-level ecological sources (Figure 4.B). Plains are typically a third-level ecological source. The ecological source areas were primarily distributed in the regions of dense mountains and sparse plains. The numbers of ecological 
373

374

375

376

377

378

379

380

381

382

383

384

385

386

387

388

389

390

391

392

393

394

395

396

397

398

399

400

401

402

403

404

405

406

407

408

409

410

411

412

413

414

415

416

sources at different levels were counted. A total of 15,38 , and 97 primary, secondary and tertiary ecological sources areas were identified, respectively. The spatial extent of primary, secondary, and tertiary ecological source areas was $27,999.21 \mathrm{~km}^{2}, 25,378.32 \mathrm{~km}^{2}$ and $15,505.07 \mathrm{~km}^{2}$, respectively. Mountainous areas provided first and second-level ecological source areas, and the plains provided third level ecological source areas. The results indicate that the habitat quality of the Beijing-Tianjin-Hebei urban agglomeration is better than that of the plains area, and the source land of the plains area is severely fragmented.

\subsection{Spatial pattern of ecological corridors and resistance surfaces}

Resistance surface modification is the core part of the development of an ecological security pattern. The Beijing-Tianjin-Hebei urban agglomeration frequently experiences geological disasters, serious soil erosion, and frequent human activities. Therefore, this study uses soil erosion sensitivity, geological hazard sensitivity and night lighting to modify the resistance surface directly based on land use patterns. The averages of the soil erosion sensitivity index, nighttime light, geological disaster sensitivity index, and resistance values of each city in the Beijing-Tianjin-Hebei urban agglomeration were calculated individually (Table 5). At the same time, the average indices of soil erosion sensitivity, nighttime light index, and geological hazard sensitivity of various land use types were calculated (Table 6).

Table 5: The averages of soil erosion sensitivity, nighttime light, geological disaster sensitivity and resistance value of each city in the Beijing-Tianjin-Hebei urban agglomeration

Table 6: Theaverages indices of soil erosion sensitivity, average nighttime light, and average geological disaster sensitivity for various land use

Higher values for soil erosion sensitivity index (Figure 5.A) were mainly distributed in the Taihang Mountains, the intermountain basins in the northwest portion of the Hebei Province, and the Yanshan Mountains in north China. The average sensitivity index of soil erosion of each land use type was measured independently. The average soil and water loss sensitivity index values of Chengde, Beijing, Qinhuangdao, and Zhangjiakou were relatively large, The average soil and water loss sensitivity index values for Tianjin, Hengshui, and Cangzhou are relatively small. The sensitivity index of soil erosion for forestland and grassland were relatively large (Table 6).

The highest values of the night light index were mainly distributed in the economically developed cities (Figure 5.B), with urbanized land having the largest average night light indices (Table 6). The average night light index values of Tianjin, Langfang, Beijing, and Tangshan were relatively large (Table 5). The average night light of Chengde and Zhangiakou were relatively small.

At a regional scale, the distribution of the sensitivity index of geological hazards was highly correlated with the macro-geomorphological gradient and the micro-topographic characteristicsof the landscape (Figure 5.C)The geological structure has a pattern of NE-SW and NW-SE directions, being higest in the NE and NW. The average geological hazard sensitivity index of Beijing and Chengde was relatively large, while that of Hengshui and Cangzhouwas relatively small (Table 5). The high values of geological hazard sensitivity were mainly distributed inforestland in the mountainous regions (Table 6).

Based on the resistance value of land use in the Beijing-Tianjin-Hebei area determined by

Peer) reviewing PDF | (2019:03:35477:2:1:NEW 13 Jun 2019) 
417 land use type and using methods described by Xie et al. (2015), the resistance value of land use 418 in the Beijing-Tianjin-Hebei urban agglomeration and its corresponding landscape resistance 419 value were determined based on the land use type (Figure 5.D). The resistance value of the forest 420 land, wetland, grassland, farmland, unused land and construction land were 10, 40, 80, 100, 500, 421800 , respectively. The revised resistance surface was calculated based on the basic resistance 422 surface, night lighting, soil erosion sensitivity index, and geological hazard sensitivity index 423 (Figure 5.E). The revised resistance surface exhibited significant changes within the same characterize the resistance differentiation of biological migration in the Beijing-Tianjin-Hebei urban agglomeration. The average resistance values of Langfang, Tianjin, and Tangshan were relatively large, while those of Chengde and Zhangjiakou were relatively small (Table 5).

Using the Linkage Mapper plug-in, the ecological source and the modified resistance surface data were input into Arcgis 10.2 to obtain a distribution map showing the locations of ecological corridors (Figure 5.F). At the same time, the length and variation of ecological corridors in each ecological city before and after the resistance surface modification are calculated (Table 7).

Table 7: Changes in the lengths of ecological corridors before and after resistance surface correction in the Beijing-Tianjin-Hebei urban agglomeration

The length of ecological corridors in some cities of the Beijing-Tianjin-Hebei region have changed significantly over time (Table 7). The length of ecological corridors in Tianjin, Tangshan, Cangzhou, and Beijing changed relatively greatly. Among them, Tianjin has experience major changes in night lighting and soil erosion, Tangshan and Beijing are greatly affected by geological hazards and night lighting, and Cangzhou is sensitive to geological hazards and soil erosion. There are 313 ecological corridors in the Beijing-Tianjin-Hebei urban agglomeration, with a total length of $9399.59 \mathrm{~km}$ (Figure 5.F). The Yanshan and Taihang mountains have a relatively high density of ecological corridors, mainly because of the good quality of the habitats, the strongest correlation between various ecological corridors in the region, and the possibility is greater that various species are able to overcome resistance and migrate, The plains area of central and southern Hebei, has a very sparse distribution of ecological corridors. This primarily occurs because the land use types in this area are mainly farmland and urbanized land with relatively poor quality habitat, and the possibility of various species being able to overcome resistance to migrateion is relatively small.

\subsection{Spatial pattern of ecological security pattern}

\subsubsection{Planning of ecological security pattern}

The spatial extent of ecological source areas determined based on the ecological services they provide was $68,882.81 \mathrm{~km}^{2} ; 63.16 \%$ of the ecological source areas was within the red line of ecological protection. The areas of overlap between the primary, secondary and tertiary ecological sources and red line ecological protection were $18,580.57 \mathrm{~km}^{2}, 14,066.25 \mathrm{~km}^{2}$, and $6723 \mathrm{~km}^{2}$, respectively. The areas where the identified ecological source area overlapped with the existing ecological protection red line areas gradually decreased over time with the reduction 
459

460

461

462

463

464

465

466

467

468

469

470

471

472

473

474

475

476

477

478

479

480

481

482

483

484

485

486

487

488

489

490

491

492

493

494

495

496

497

498

499

500

501

502

of the level of ecological source area, indicating the rationality of the identification of ecological source areas. Figure 5.F shows that the corridors between the plains are relatively long, the ecological source base is basically the third-level ecological source, and the area of ecological source is less. Therefore, it is suggested to add radiation sources on the basis of the original ecological source. The primary ecological source area is arcuate along Yanshan and Taihang mountains. Attention should be paid to the protection of habitats in the aforementioned areas due to their large size and the short ecological corridor. The secondary ecological sources are mainly distributed in the northern mountains of Heibei Province, here, regional habitat restoration should be given more attention, with the goal of forming an ecological security pattern for the Beijing-Tianjin-Hebei urban agglomeration with reasonable spatial distribution and enhanced ecological service functions.

Figure 5: Spatial patterns of resistance surface and ecological corridors: Spatial patterns of (A) soil and water loss sensitivity, (B) night lighting, (C) geological hazard sensitivity index, (D) basic resistance surface, $(\mathrm{E})$ corrected resistance surface, and (F) ecological source level and ecological corridors

\subsubsection{Contrast with the existing ecological security pattern}

As noted above, the red line of ecological protection refers to China's strict landuse control boundary demarcated by law for important ecological functional and sensitive areas and vulnerable areas, providing the last line of defense for national and regional ecological security. By geometric correction of the spatial pattern of this ecological protection red line, the delineation of this red line in the analyzed urban area was obtained by vectorization (Figure 6.A). In the Beijing-Tianjin-Hebei urban agglomeration the ecological protection red line area covers $62,329.78 \mathrm{~km}^{2}$, with a total length of the ecological red line corridor of $2670.57 \mathrm{~km}$. Because the ecological red line corridors are relatively small, this study defines expressways, rivers, and the ecological red line corridor as the current corridor. The habitat in this vector includes forestland, grassland, and wetland in the ecological red line area; it includes nature reserves, water conservation areas, large-scale ecological land use areas and is based on land use data in the Beijing-Tianjin-Hebei planning outline that were regionally vectorized and superimposed. The ecological source area within the study area was extracted and found to cover $4689.72 \mathrm{~km}^{2}$. Combined with the revised resistance surface, an ecological corridor with human interference factors was generated Figure 7.A, Figure 7.D, Figure 7.G and Figure 7.J, and the ecological corridor considering the ecological service separately is generated by combining the basic resistance surface as shown in Figure 7.B, Figure 7.E, Figure 7.H and Figure 7.K, the ecological corridor considering the ecological service and human interference factors synthetically is generated by combining the modified resistance surface, as shown in Figure 7.C, Figure 7.F, Figure 7.I and Figure 7.L, respectively. The length of the three ecological corridors and their overlap with the ecological red line corridor and the current corridors are shown in Table 8.

Table 8: Comparison of ecological corridor length

The distribution of ecological corridors was generally consistent when the three methods of delineating corridors were compared (Figure 6.B and Table 8). Because of differences in human disturbance and ecological services available in some areas, in this study, the overlapping lengths

Peer] reviewing PDF | (2019:03:35477:2:1:NEW 13 Jun 2019) 
503

504

505

506

507

508

509

510

511

512

513

514

515

516

517

518

519

520

521

522

523

524

525

526

527

528

529

530

531

532

533

534

535

536

537

538

539

540

541

542

543

544

of the ecological corridors identified by ecosystem services and human interference factors and the current corridor became significantly longer, indicating that comprehensive consideration of ecological services and human interference factors can improve the identification of ecological corridors in urban agglomerations.

Figure 6: Comparison of ecological security pattern: (A) The present spatial ecological security pattern and (B) the comprehensive ecological security pattern of the Beijing-TianjinHebei urban agglomeration.

Figure 7: Comparison of ecological corridors: Spatial pattern of (A) human disturbance and ecological red line corridors; (B) ecological service and ecological red line corridors; (C) human disturbance and ecological services and ecological red line corridors; (D) human disturbance and river; (E) ecological service and river; (F) human disturbance and ecological services and river;

(G) human disturbance and expressway; (H) ecological service and expressway; (I) human disturbance and ecological services and expressway. Mapping of how the current corridor of the Beijing-Tianjin-Hebei urban agglomeration coincides with: (J) human disturbance corridor; (K) ecological services corridor; (L) human disturbance and ecological services corridor.

\section{Discussion}

\subsection{Determination of ecological sources and level of ecological sources}

In terms of ecological source identification Special Protection Areas (SPA) of the Natura 2000 network that contain forests and agroforest mosaics were selected as core areas to be connected through ecological corridors at a regional scale in the Basque Country (Gurrutxaga et al., 2010). This method of directly selecting nature reserves as the core ecological source focuses on considering the functional properties of ecological land patches, but does not consider the spatial structure importance of the ecological source in the whole landscape and the relationship with the surrounding environment. This research effort main goal was to quantitatively evaluate the functions of ecological services, water production services, soil and water conservation services and leisure services on the basis of absorbing the methods of considering the importance of ecological services in the past, taking into account the importance of the ecological source itself and its structure in the landscape pattern. In the selection of ecological service factors, Zhang (2016) selected biodiversity service, soil conservation service and water resource security combining the natural environment characteristics of Beijing-Tianjin-Hebei urban agglomeration. On this basis, this paper combines the research results of Peng (2018) and the ecological protection red line technical guidelines delineated by the Ministry of Environmental Protection of China. Thereby enriching the ecological service supply of the Beijing-Tianjin-Hebei urban agglomeration. In terms of ecological source identification, Zhang (2016) proposed a new evaluation framework integrating ecosystem services importance assessment and landscape connectivity analysis with human ecological demand importance assessment to identify ecological sources. This paper introduces logical coding to establish the spatial relationship between the ecological source and its corresponding ecological services, and describes the spatial pattern of the two by spatial rasterization. Based on logic coding, the ecological service logic map and the ecological source map of importance are generated. From the ecological service 
545 logic map, what ecological services are available in the ecological source area can be judged by 546 the location of " 1 ," " 0 " and its " 1 " and " 0 ". From the ecological source map of importance, the 547 ecological source level can be derived. This is of great significance for the management of 548 refined ecological sources.

\subsection{Selection of human interference factors}

In recent years, the modification of a resistance surface that considers specific ecological problems for specific regions has become an important area of research in the optimization of ecological security patterns. For example, Zhang (2016) used night light data to modify the ecological resistance surface in the Beijing-Tianjin-Hebei urban agglomeration. Peng (2018) used an imperious index to modify the ecological resistance surface in Shenzhen, China. A surface wetting index was used to modify the ecological resistance surface for pastoral farming areas in semi-arid regions of China (Peng et al., 2018). Many scholars studied the influence of spatial differences caused by specific ecological problems in different regions on species migration; these factors are collectively referred to as human interference factors, which are used to express the degree of impact that human activities cause to natural environments. For small regions, the effects of a single factor on species migration can be considered for specific ecological environment problems. However, an analysis of the relatively large ecosystem of the Beijing-Tianjin-Hebei urban agglomeration needs to take into account the protection of biodiversity, the restoration of degraded ecosystems, and the sustainable development of the social economy. The purpose of the present study is to systematically help land managers solve regional environmental problems. The singular problems of environmental pollution or biological resources protection have been extended to the systematic analysis and comprehensive study of regional ecological environment problems (Franklin, 1993). Borders of mountains, plains and plateaus can be seen from Figure 4.B. The plateau is located in a small part of the northwest direction of the study area. The plain is located in most of the southwest direction, and the middle part of the plain and plateau is the mountain. The human interference factors selected in this paper include soil erosion sensitivity, geological hazard sensitivity and nighttime light index. It can be seen from the results in Figure 5.A, Figure 5.B and Figure 5.C that the areas of this high geological hazard while soil erosion sensitivity are concentrated in the mountainous areas of urban agglomeration, and the areas of high night light are concentrated in the plains area. The established resistance surface considers the human activity situation of the entire area of Beijing-Tianjin-Hebei. So the results highlight that the selected human interference factor is relatively reasonable.

\section{Conclusion}

Based on ecosystem services and human disturbance factors, this study defined the ecological security pattern of the Beijing-Tianjin-Hebei urban agglomeration, which provides a new holistic framework. The main content of this study include the use of ecosystem services to determine ecological sources, and the establishment of the logical relationship between ecological sources and ecosystem services. Additionally, ecological corridors were identified using a minimum cumulative resistance model based on sources and resistance surface modified through human disturbance factors. The results show that water production, soil and water conservation, and carbon fixation sources were mainly distributed in mountainous regions of the study area, recreational sources were mostly distributed in the plains, and the extracted 
589

590

591

592

593

594

595

596

597

598

599

600

601

602

603

604

605

606

607

608

609

610

611

612

613

614

615

616

617

618

619

620

621

622

623

624

625

626

627

628

629

630

631

632

633

634

ecological sources improve the recognition of ecological corridors. The modification of resistance surface makes the length of ecological corridors in Tianjin, Tangshan, Cangzhou, and Beijing change significantly, while this modified resistance surface improves the recognition of ecological corridors. Based on the importance of the divided ecological sources and the identified ecological corridors, this study proposes some planning suggestions for the existing ecological security pattern with the goal of forming a reasonable spatial layout and improving the ecological service function of the ecological security pattern of this agglomeration.

Future research of the proposed methodology contains 3 aspects: a) a more analytical ecological source identification is that comprehensive consideration of the trade-off and synergy of ecological services to identify the level of ecological source. b) In terms of resistance surface correction, the nighttime light index is used to directly correct the resistance surface based on land use, the soil erosion sensitivity index is used to correct the resistance surface based on land use, and the resistance surface based on land use is corrected by geological disaster sensitivity. The length of the ecological corridor and the coincidence length of the actual ecological corridor, explore the degree of influence of different human interference factors on the resistance surface. c) In the aspect of ecological corridor extraction, the identified ecological source level is introduced into the gravity model, and the traditional gravity model is improved to make the identified ecological corridor more scientific and reasonable.

\section{References}

Han B, Liu H, Wang R. 2005. Urban ecological security assessment for cities in the BeijingTianjin-Hebei metropolitan region based on fuzzy and entropy methods. Ecological Modelling 318:217-225 DOI 10.1016/j.ecolmodel.2014.12.015.

Cumming G S, Allen C R, 2017. Protected areas as social-ecological systems: perspectives from resilience and social-ecological systems theory. Ecological Applications 27(6):1709-1717 DOI 10.1002/eap.1584.

Peng J, Yang Y, Liu YX, Hu YN, Du YY. 2018. Linking ecosystem services and circuit theory to identify ecological security patterns. Science of the Total Environment 644:781-790 DOI 10.1016/j.scitotenv.2018.06.292.

Li JX, Song CH, Cao LU, Zhu FG, Meng XL, Wu JG. 2011. Impacts of landscape structure on surface urban heat islands: a case study of Shanghai, China. Remote Sens Environ. Remote Sensing of Environment 115(12):3249-3263 DOI 10.1016/j.rse.2011.07.008.

Ahern J. 1995. Greenways as a planning strategy. Landscape \& Urban Planning 33(1-3):131-155. Zube E H. 1995. Greenways and the US National Park system. Landscape \& Urban Planning 33(1-3):0-25.

Albanese G, Haukos D A. 2016. A network model framework for prioritizing wetland conservation in the Great Plains. Landscape Ecology 32(1):1-16 DOI: 10.1007/s10980-0160436-0.

Miao CY, Ashouri H, Hsu K, Sorooshian S, Duan QY, 2015. Evaluation of the PERSIANNCDR daily rainfall estimates in capturing the behavior of extreme precipitation events over China. Journal of Hydrometeorology 16(3):1387-1396 DOI 10.1175/JHM-D-14-0174.1.

Dalang T, Hersperger A M. 2012. Trading connectivity improvement for area loss in patch-based biodiversity reserve networks. Biological Conservation 148(1):116-125.

Gaaff A, Reinhard S. 2012. Incorporating the value of ecological networks into cost-benefit analysis to improve spatially explicit land-use planning. Ecological Economics 73(1):66-74.

Dong JH, Dai WT, Shao GQ, Xu JR. 2015. Ecological Network Construction Based on

Peer] reviewing PDF | (2019:03:35477:2:1:NEW 13 Jun 2019) 
635 Minimum Cumulative Resistance for the City of Nanjing, China. ISPRS International Journal of 636 Geo-Information 4(4):2045-2060 DOI 10.3390/ijgi4042045.

637 Kang W, Minor E S, Lee D, Park CR. 2016. Predicting impacts of climate change on habitat 638 connectivity of Kalopanax septemlobus, in South Korea. Acta Oecologica 71:31-38 DOI 639 10.1016/j.actao.2016.01.005.

640 Zhang LQ, Peng J, Liu YX, Wu JS1. 2017. Coupling ecosystem services supply and human 641 ecological demand to identify landscape ecological security pattern: A case study in Beijing642 Tianjin-Hebei region, China. Urban Ecosystems 20(3):1-14 DOI 10.1007/s11252-016-0629-y.

643 Jing YC, Chen LD, Sun RH. 2018. A theoretical research framework for ecological security 644 pattern construction based on ecosystem services supply and demand. Acta Ecologica sinica 645 38(12):4121-4131 DOI 10.5846/stxb201803090469 (in Chinese).Klar N , Herrmann M , 646 Henning-Hahn M, Pott-Dorfer B, Hofer H, Kramer-Schadt S. 2012. Between ecological theory 647 and planning practice: (Re-) Connecting forest patches for the wildcat in Lower Saxony, 648 Germany. Landscape and Urban Planning 105(4):0-384 DOI 10.1016/j.landurbplan.2012.01.007.

$649 \mathrm{Gu}$ ZJ, Duan XW, Liu B, Hu JM, He JN. 2016. The spatial distribution and temporal variation of 650 rainfall erosivity in the Yunnan Plateau, Southwest China: 1960-2012. Catena. 145: 291-300 651 DOI 10.1016/j.catena.2016.06.028

652 Yang Y, Wang L, Wendroth O, Liu B, Cheng C, Huang T, Shi Y. 2018. Is the laser diffraction 653 method reliable for soil particle size distribution analysis? An evaluation by sieve-pipette method 654 and scanning electron microscopy. Soil Sci. Soc. Am. J. Doi 10.2136/sssaj2018.07.0252.

655 Teng MJ, Wu CG, Zhou ZX, Lord E Zheng ZM. 2011. Multipurpose greenway planning for 656 changing cities: A framework integrating priorities and a least-cost path model. Landscape and 657 Urban Planning 103(1):0-14 DOI 10.1016/j.landurbplan.2011.05.00.

658 Gurrutxaga M, Lozano PJ, Barrio GD. 2010. GIS-based approach for incorporating the 659 connectivity of ecological networks into regional planning. Journal for Nature Conservation 660 18(4):318-326 DOI 10.1016/j.jnc.2010.01.005.

661 Su YX, Chen XZ, Liao JS, Zhang HG, Wang CJ Ye YY, Wang Y. 2016. Modeling the optimal 662 ecological security pattern for guiding the urban constructed land expansions. Urban Forestry \& 663 Urban Greening 19:35-46 DOI 10.1016/j.ufug.2016.06.013.

664 Kong FH, Yin HW, Nakagoshi N, Zong YG. 2010. Urban green space network development for 665 biodiversity conservation: Identification based on graph theory and gravity modeling. Landscape 666 and Urban Planning 95(1-2):0-27 DOI 10.1016/j.landurbplan.2009.11.001.

667 Chen L, Fu B , Zhao W . Source-sink landscape theory and its ecological significance[J]. 668 Frontiers of Biology in China, 2008, 3(2):131-136.

669 Wu JS, Zhang LQ, Peng J, Feng Z, Liu HM, Hao SB. 2013. The integrated recognition of the 670 source area of the urban ecological security pattern in Shenzhen. Acta Ecologica Sinica,

672 Daily G C. 1997. Nature's Sercice : Social Dependence on Natural Ecosystem. Washington DC: 673 Island Press.

674 Egoh BN, Reyers B. 2008. Mapping ecosystem services for planning and management: A 675 biogeographical approach. Agriculture Ecosystems \& Environment 127(1):135-140.

676 Bennett EM, Peterson GD, Gordon LJ. 2009. Understanding relationships among multiple 677 ecosystem services. Ecology Letters 12(12):1394-1404 DOI 10.1111/j.1461-0248.2009.01387.x. 678 Raudsepp-Hearne C, Peterson G D, Bennett E M. 2010. Ecosystem service for analyzing 679 tradeoffs in diverse landscapes. Proceedings of the National Academy of Sciences 107(11):52426805247. 
681 Kareiva P, Watts S, Mcdonald R, Boucher T. 2007. Domesticated Nature: Shaping Landscapes

682 and Ecosystems for Human Welfare. Science 316(5833):1866-1869 DOI

683 10.1126/science.1140170.

684 Knaapen JP, Scheffer M, Harms B. 1992. Estimating habitat isolation in landscape planning.

685 Landscape \& Urban Planning 23(1):1-16 DOI 10.1016/0169-2046(92)90060-D.

686 Yu KJ. 1999. Landscape ecological security patterns in biological conservation. Acta Ecologica

687 Sinica 19(1):8-15DOI 10.3321/j.issn:1000-0933.1999.01.002.

688 Beni LH, Villeneuve S, Leblanc DI, Delaquis P. 2011. A GIS-based Approach in Support of an

689 Assessment of Food Safety Risks. Transactions in Gis 15(Supplement s1):95-108 DOI 690 10.1111/j.1467-9671.2011.01264.x.

691 Aretano R, Semeraro T, Petrosillo I, Marco AD, Pasimeni MR, Zurlini G. 2015. Mapping 692 ecological vulnerability to fire for effective conservation management of natural protected areas. 693 Ecological Modelling 295(Sp. Iss. SI):163-175 DOI 10.1016/j.ecolmodel.2014.09.017.

694 Fu W, Liu SL, Degloria SD, Dong SK, Beazley R. 2010. Characterizing the "fragmentation695 barrier" effect of road networks on landscape connectivity: A case study in Xishuangbanna, 696 Southwest China. Landscape and Urban Planning 95(3):0-129 DOI 697 10.1016/j.landurbplan.2010.06.005.

698 Peng J, Pan YJ, Liu YX, Zhao HJ, Wang YL. 2018. Linking ecological degradation risk to 699 identify ecological security patterns in a rapidly urbanizing landscape. Habitat International $700 \quad 71: 110-124$.

701 Li YF, Sun XA, Zhu XD. 2010. An early warning method of landscape ecological security in 702 rapid urbanizing coastal areas and its application in Xiamen, China. Ecological Modelling 221(19):2251-2260 DOI 10.1016/j.ecolmodel.2010.04.016.

Yu Q, Yue DP, Wang YH, Kai S, Fang MZ, Ma H, Zhang QB, Huang Y. 2018. Optimization of ecological node layout and stability analysis of ecological network in desert oasis : a typical case study of ecological fragile zone located at Deng Kou County(Inner Mongolia). Ecological Indicators 84:304-318 DOI10.1016/j.ecolind.2017.09.002.

Chen LD, Jing YC, Sun RH. 2018. Urban eco-security pattern construction:targets,principles and basic framework. Acta Ecologica Sinica 38( 12):4101-4108 DOI 10.5846/stxb201802270395(in Chinese).

Gong JZ, Liu YS, Xia BC, Zhao GW. 2009. Urban ecological security assessment and forecasting, based on a cellular automata model: A case study of Guangzhou, China. Ecological Modelling, 220(24):3612-3620 DOI 10.1016/j.ecolmodel.2009.10.018.

Liu SH, Wang DY, Li H, Li WB, Wu WJ, Zhu YL. 2017. The Ecological Security Pattern and Its Constraint on Urban Expansion of a Black Soil Farming Area in Northeast China. ISPRS International Journal of Geo-Information 6(9) DOI 10.3390/ijgi6090263.

Duan XW, Zhang GL, Li R, Fang HY, He DM, Feng DT. 2015. Spatial distribution and environmental factors of catchment-scale soil heavy metal contamination in the dry-hot valley of Upper Red River in southwestern China. Catena 135: 59-69 DOI 10.1016/j.catena.2015.07.006. Chen Z, Jiang WG, Wang WJ, Deng Y, He B, Jia K. 2017. The Impact of Precipitation Deficit and Urbanization on Variations in Water Storage in the Beijing-Tianjin-Hebei Urban Agglomeration. Remote Sensing 10(1) DOI 10.3390/rs 10010004.

Miao CY, Ni JR, Borthwick AGL, Yang L. 2011. A preliminary estimate of human and natural contributions to the changes in water discharge and sediment load in the Yellow River. Global and Planetary Change 76(3-4): 196-205 DOI 10.1016/j.gloplacha.2011.01.008.

Meng H, Li CY, Zhang RL, Li YM. 2017. Risk assessment of geological hazards for counties

Peer] reviewing PDF | (2019:03:35477:2:1:NEW 13 Jun 2019) 
727

728

729

730

731

732

733

734

735

736

737

738

739

740

741

742

743

744

745

746

747

748

749

750

751

752

753

754

755

756

757

758

759

760

761

762

and districts of the Beijing-Tianjin-Hebei region. Progress In Geography 36(03):327-334 DOI 10.18306/dlkxjz.2017.03.008 (in Chinese).

Ou Yang ZY, Wang XK, Miao H. 2000. China 's eco-environmental sensitivity and its spatial heterogeneity. Acta Ecologica Sinica 20(01):9-12 (in Chinese).

Mellander C, Lobo J, Stolarick K, Matheson Z. 2015. Night-Time Light Data: A Good Proxy Measure for Economic Activity?. PLOS ONE 10(10) DOI 10.1371/journal.pone.0139779.

Miao CY, Ni JR, Borthwick A G L. 2010. Recent changes of water discharge and sediment load in the Yellow River basin, China. Progress in Physical Geography 34(4):541-561 DOI $10.1177 / 0309133310369434$.

Kuang WH. 2018. Impervious surface-vegetation index-vegetation net primary productivity data set in Beijing-Tianjin-Hebei urban agglomeration. Journal of Global Change Data DOI 10.3974/geodb.2018.05.06.V1.

Gao S, Liu QH, Kang J, Zhao J, Li J, Zhong B, Peng JJ. 2017. China-ASEAN 1 km resolution vegetation net primary productivity data set (2013). Journal of Global Change Data 1(3): 303308. DOI 10.3974/geodp.2017.03.08.

Wischmeier WH, Smith DD. 1965. Predicting rainfall erosion from cropland East of the Rocky mountains-guide for selection of practices for soil and water conservation. Agricultural Handbook. US Department of Agriculture, Washington DC(NO.282).

Peng J, Li HL, Liu YX, Hu YN, Yang Y. 2018. Identification and optimization of ecological security pattern in Xiong'an New Area. Acta Geographica Sinica 73(4):701-710 DOI 10.11821/dlxb201804009 (in Chinese).

Yang SS, Zhou CX, Shen WS, Shen RP, Xu DL. 2016. Construction of ecological security patterns based on ecological red line: A case study of Jiangxi Province. Chinese Journal of Ecology 35( 1):250-258 DOI 10.13292/j.1000-4890.201601.034 (in Chinese).

Saaty T L. 1987. Principles of the analytic hierarchy process. Expert judgment and expert systems 27-73 DOI 10.1007/978-3-642-86679-1_3.

Xie GD, Zhang CX, Zhang LM, Chen WH, Li SM. 2015. Improvement of the Evaluation Method for Ecosystem Service Value Based on Per Unit Area. Journal of Natural Resources 30(8):1243-1254 DOI 10.11849/zrzyxb.2015.08.001 (in Chinese).

Peng J, Jia JL, Hu YN, Tian L, Li HL. 2018. Construction of ecological security pattern in the agro-pastoral ecotone based on surface humid index: A case study of Hangjin Banner, Inner Mongolia Autonomous Region, China 29(6):1990-1998 DOI 10.13287/j.1001-9332.201806.015 (in Chinese).

Franklin JF. 1993. Preserving biodiversity:Species, ecosystems, or landcapes. Ecological Applications 3:202-205. 
Table $\mathbf{1}$ (on next page)

Data sources 


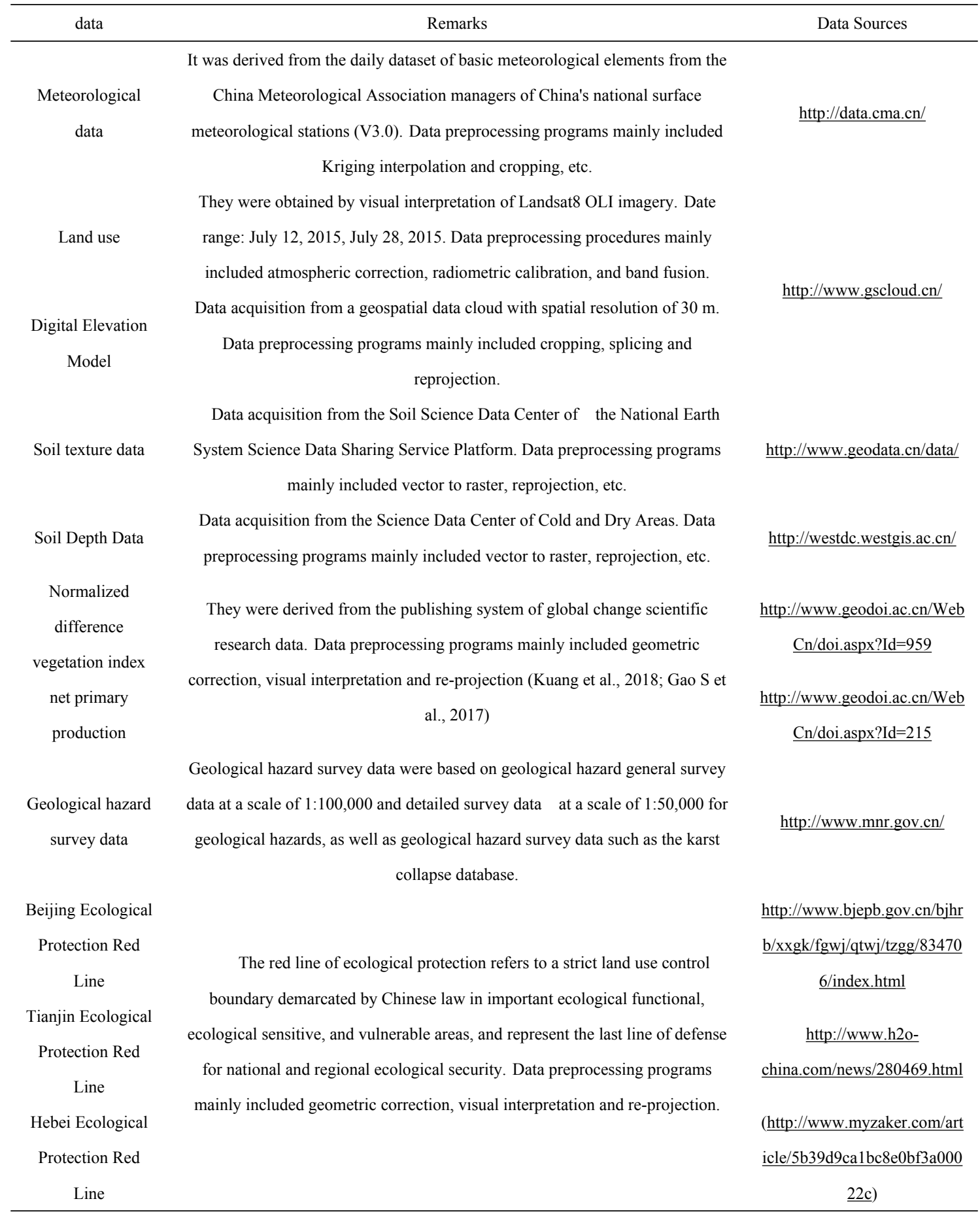

2 
Table 2 (on next page)

Weight of various factors of geological hazard sensitivity 
1 Table 2 Weight of various factors of geological hazard sensitivity

\begin{tabular}{|c|c|c|c|}
\hline $\begin{array}{l}\text { Decision } \\
\text { objective }\end{array}$ & Interlayer element & Alternative & Weight \\
\hline \multirow{9}{*}{$\begin{array}{c}\text { Geological } \\
\text { hazard } \\
\text { sensitivity }\end{array}$} & \multirow{3}{*}{ Disaster } & Density of geological hazards & 0.1908 \\
\hline & & Euclidean distance of faults & 0.1349 \\
\hline & & Earthquake acceleration & 0.1099 \\
\hline & \multirow{3}{*}{ Terrain } & Slope & 0.156 \\
\hline & & Waviness & 0.0912 \\
\hline & & Slope position & 0.0632 \\
\hline & \multirow{3}{*}{ Other } & Engineering rock group & 0.1109 \\
\hline & & Normalized difference vegetation index & 0.0743 \\
\hline & & Precipitation & 0.0689 \\
\hline
\end{tabular}

2

3 
Table 3 (on next page)

Area and proportion of different levels of ecosystem services 
1 Table 3 Area and proportion of different levels of ecosystem services

\begin{tabular}{|c|c|c|c|c|c|c|c|c|}
\hline & $\begin{array}{l}\text { Carbon } \\
\text { fixation } \\
\text { service }\end{array}$ & & $\begin{array}{c}\text { Soil and water } \\
\text { conservation } \\
\text { service }\end{array}$ & & $\begin{array}{c}\text { Water } \\
\text { production } \\
\text { service }\end{array}$ & & $\begin{array}{c}\text { Leisure and } \\
\text { recreational } \\
\text { service }\end{array}$ & \\
\hline & Area $\left(\mathrm{km}^{2}\right)$ & $\begin{array}{c}\text { Proportion } \\
(\%)\end{array}$ & Area $\left(\mathrm{km}^{2}\right)$ & $\begin{array}{c}\text { Proportion( } \\
\%)\end{array}$ & Area $\left(\mathrm{km}^{2}\right)$ & $\begin{array}{c}\text { Proportion } \\
(\%)\end{array}$ & Area $\left(\mathrm{km}^{2}\right)$ & $\begin{array}{c}\text { Proportion } \\
(\%)\end{array}$ \\
\hline $\begin{array}{l}\text { Generally } \\
\text { important }\end{array}$ & 30006.56 & $13.88 \%$ & 167863.23 & $78.31 \%$ & 100565.55 & $46.97 \%$ & 4869.16 & $2.25 \%$ \\
\hline $\begin{array}{l}\text { Slightly } \\
\text { important }\end{array}$ & 79240.88 & $36.66 \%$ & 11425.31 & $5.33 \%$ & 64397.39 & $30.08 \%$ & 5784.58 & $2.68 \%$ \\
\hline $\begin{array}{c}\text { Moderately } \\
\text { important }\end{array}$ & 77111.86 & $35.67 \%$ & 9489.43 & $4.43 \%$ & 17910.11 & $8.37 \%$ & 6724.76 & $3.11 \%$ \\
\hline $\begin{array}{c}\text { Highly } \\
\text { important }\end{array}$ & 9691.46 & $4.48 \%$ & 7389.25 & $3.45 \%$ & 17691.88 & $8.26 \%$ & 7697.28 & $3.56 \%$ \\
\hline $\begin{array}{l}\text { Extremely } \\
\text { important }\end{array}$ & 20117.15 & $9.31 \%$ & 18180.17 & $8.48 \%$ & 13528.04 & $6.32 \%$ & 8701.79 & $4.03 \%$ \\
\hline
\end{tabular}

2 


\section{Table 4 (on next page)}

Area and proportion of logical coding of ecological service categories 
Table 4 Area and proportion of logical coding of ecological service categories

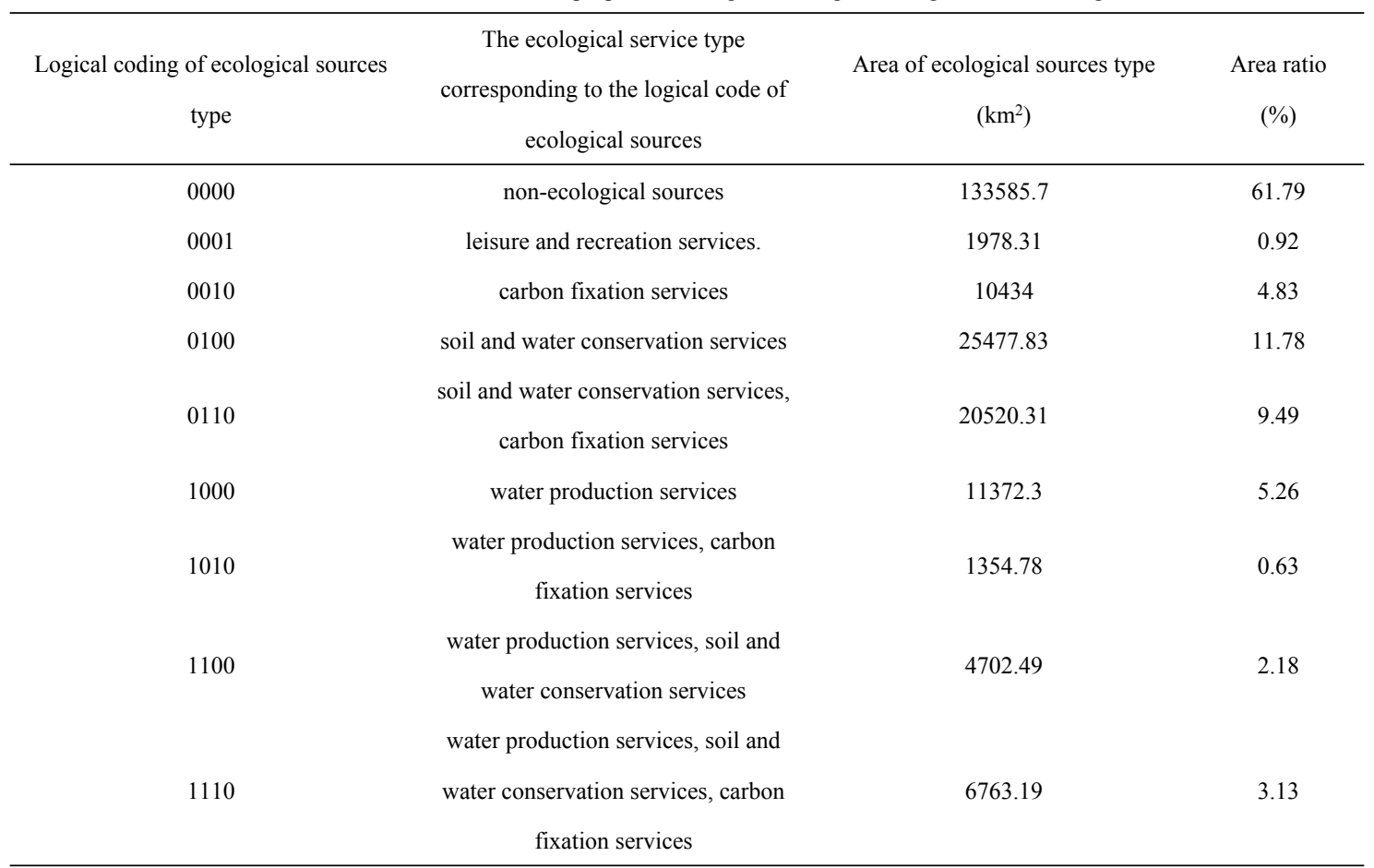

2 


\section{Table 5 (on next page)}

The average soil erosion sensitivity 
1 Table 5 The average soil erosion sensitivity, average nighttime light, average geological disaster sensitivity and average resistance value of each city in the 2 Beijing-Tianjin-Hebei urban agglomeration

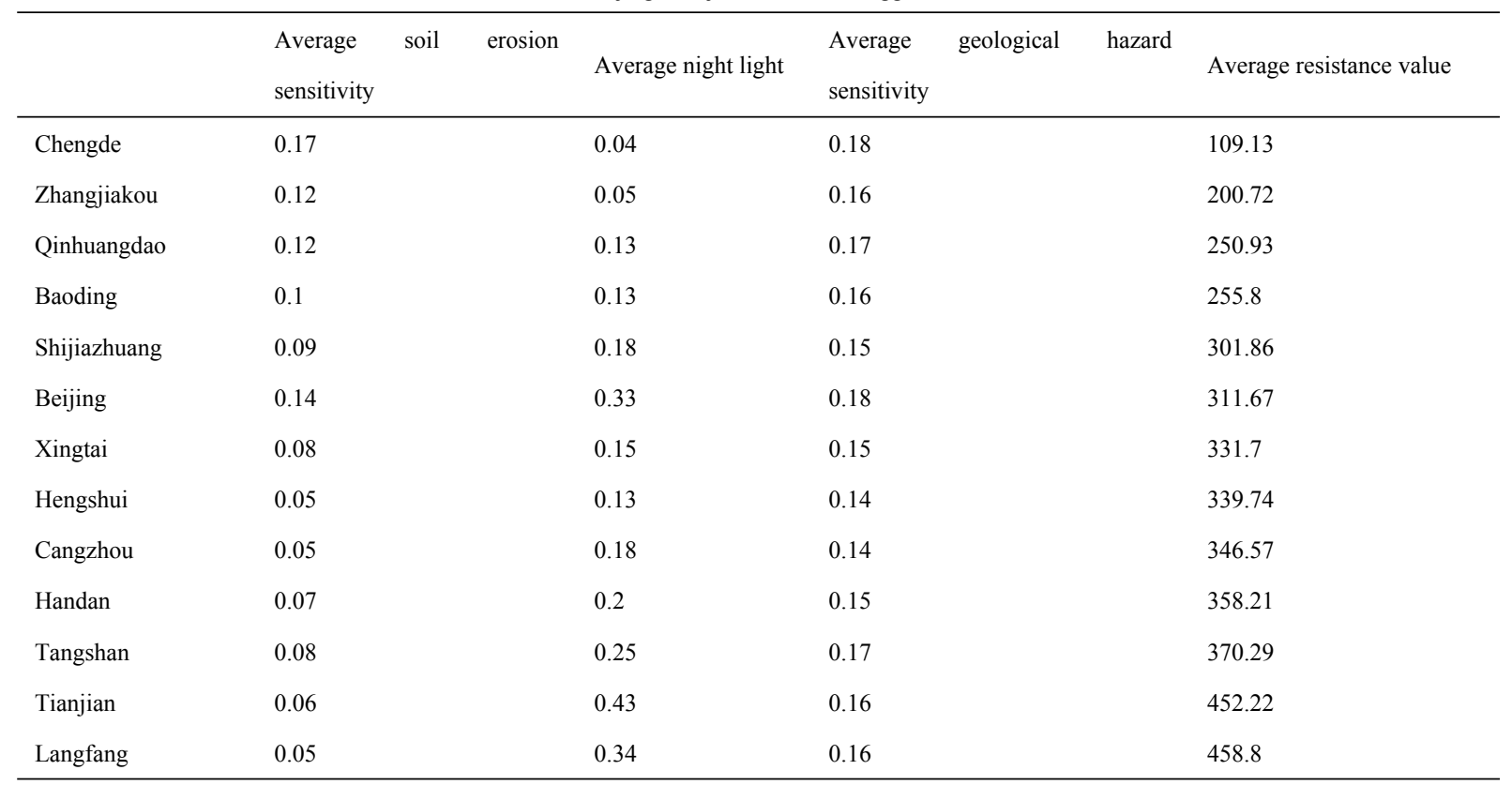

3 


\section{Table 6(on next page)}

The average soil erosion sensitivity index, average nighttime light index, average geological disaster sensitivity index of various land use 
Table 6 The average soil erosion sensitivity index, average nighttime light index, average geological disaster sensitivity index of various land use

\begin{tabular}{llll}
\hline & Average soil erosion sensitivity & Average night light & Average geological hazard sensitivity \\
\hline Forest land & 0.17 & 0.05 & 0.19 \\
Wetland & 0.04 & 0.26 & 0.14 \\
Grassland & 0.11 & 0.07 & 0.17 \\
Farmland & 0.07 & 0.17 & 0.15 \\
Unused land & 0.08 & 0.18 & 0.14 \\
Construction land & 0.06 & 0.42 & 0.15 \\
\hline
\end{tabular}

2 


\section{Table 7 (on next page)}

Changes of ecological corridor length before and after resistance surface correction in Beijing $\square$ Tianjin $\square$ Hebei urban agglomeration 


\begin{tabular}{lllll} 
Cities & $\begin{array}{l}\text { Ecological corridor } \\
\text { length }(\mathrm{km})\end{array}$ & $\begin{array}{l}\text { Ecological corridor length } \\
\text { services }, \text { human disturbance) }\end{array}$ & $\begin{array}{l}\text { (Ecological } \\
\text { Variation of length of ecological } \\
\text { corridor }(\mathrm{km})\end{array}$ \\
\hline Qinhuangdao & 194.61 & 340.51 & 111.05 \\
Chengde & 581.49 & 200 & 5.39 \\
Zhangjiakou & 961.83 & 657.57 & 76.08 \\
Baoding & 1088.64 & 996.24 & 34.41 \\
Tianjin & 887.56 & 1148.05 & 59.41 \\
Tangshan & 723.53 & 1145.76 & 258.2 \\
Langfang & 272.36 & 966.85 & 243.32 \\
Shijiazhuang & 1727.98 & 332.85 & 60.49 \\
Cangzhou & 371.11 & 1752.52 & 24.54 \\
Hengshui & 260.15 & 507.12 & 136.01 \\
Xingtai & 818.62 & 297.73 & 37.58 \\
Handan & 171.66 & 915.7 & 97.08 \\
\hline
\end{tabular}

2 
Table 8(on next page)

Comparison of ecological corridor length 
1 Table 8 Comparison of ecological corridor length

\begin{tabular}{cccc}
\hline & $\begin{array}{c}\text { Ecological Corridor } \\
(\mathrm{km})\end{array}$ & $\begin{array}{c}\text { Ecological Red Corridor Overlap } \\
(\mathrm{km})\end{array}$ & Current Corridor Overlap (km) \\
\hline Ecological Service & 8515.68 & 1390.06 & 4680.62 \\
Human Disturbance & 10626.34 & 1545.83 & 4751.52 \\
Ecological Service and Human & & & 5458.98 \\
Disturbance & 9399.59 & 1538.76 & \\
\hline
\end{tabular}

2 
Figure 1

\section{Overview of the construction of ecological security pattern}

Flow chart of ecological security pattern construction. Arrows indicate the relationship between the various elements.

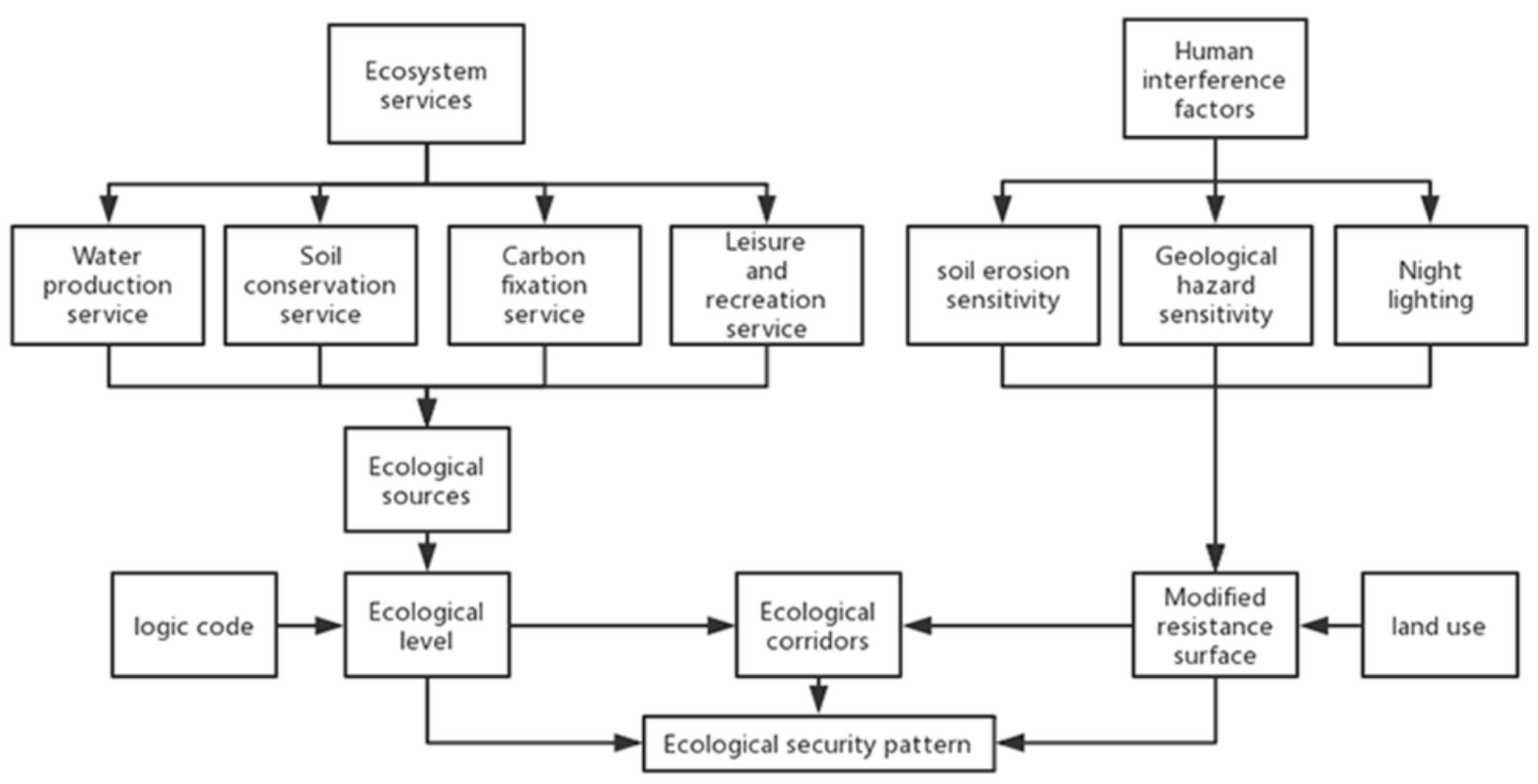


Figure 2

Location of the Beijing-Tianjin-Hebei urban agglomeration and Digital Elevation Model (DEM) of the study area

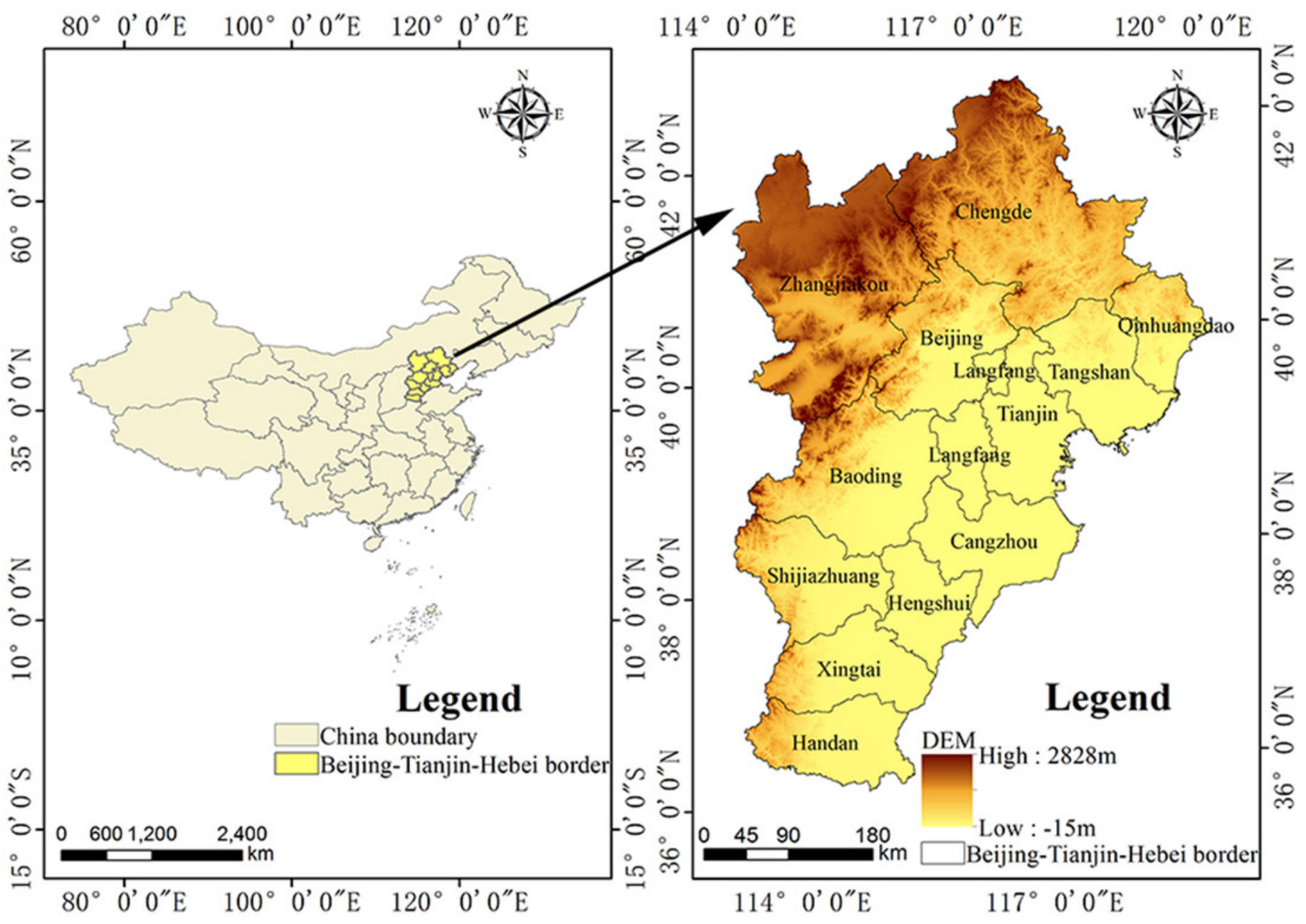


Figure 3

Spatial patterns of ecological services.

Spatial patterns of (A) water production, (B) soil and water conservation, (C) carbon fixation, (D) leisure and recreation services.
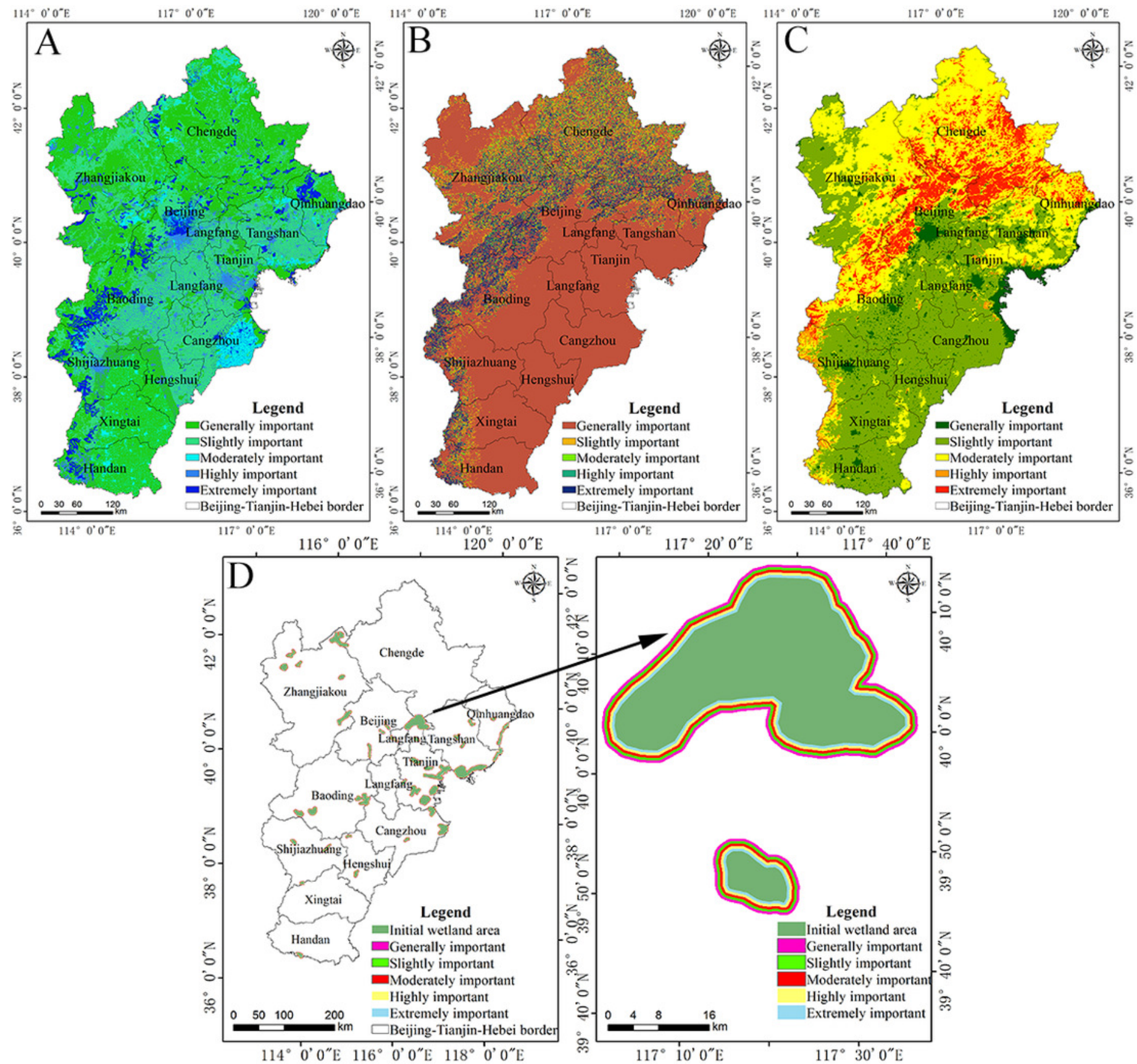
Figure 4

Spatial patterns of ecological sources.

Spatial patterns of the (A) logical coding of ecological service categories and (B) levels of ecological sources.
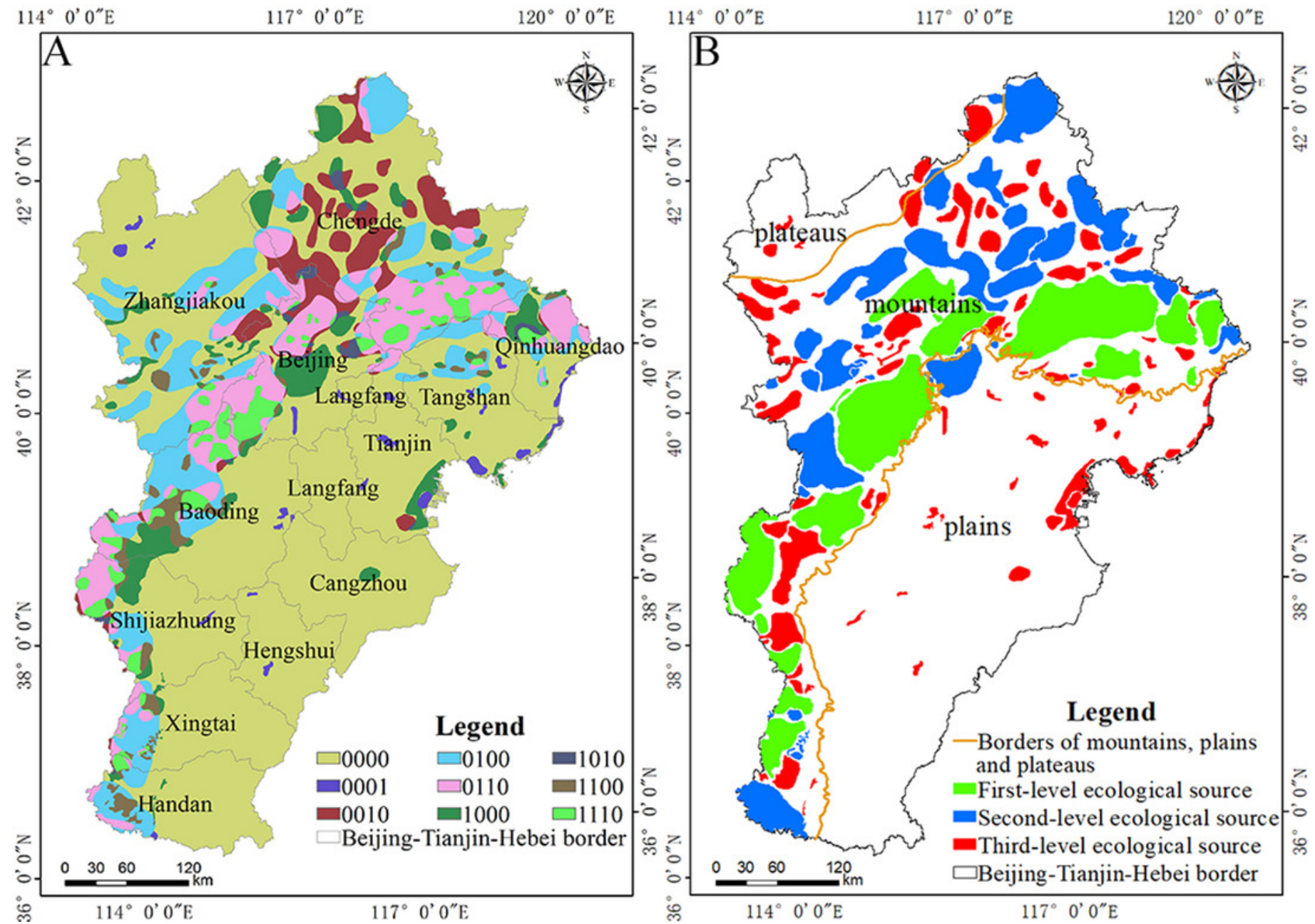


\section{Figure 5}

\section{Spatial patterns of resistance surface and ecological corridors.}

Spatial patterns of (A) soil and water loss sensitivity, (B) night lighting, (C) geological hazard sensitivity index.
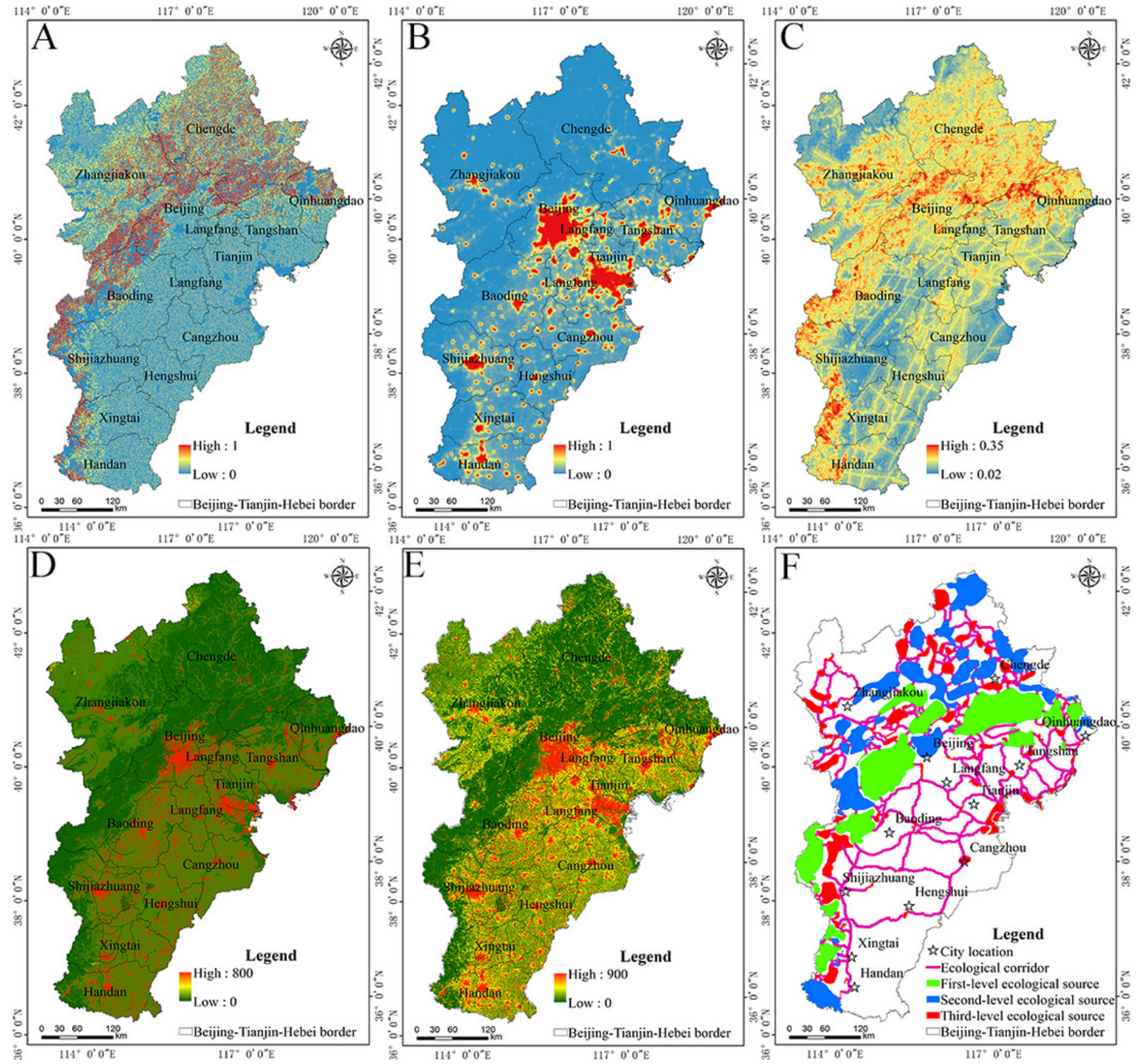
Figure 6

Comparison of ecological security patterns.

(A) The present spatial ecological security pattern and (B) the comprehensive ecological security pattern of the Beijing-Tianjin-Hebei urban agglomeration.

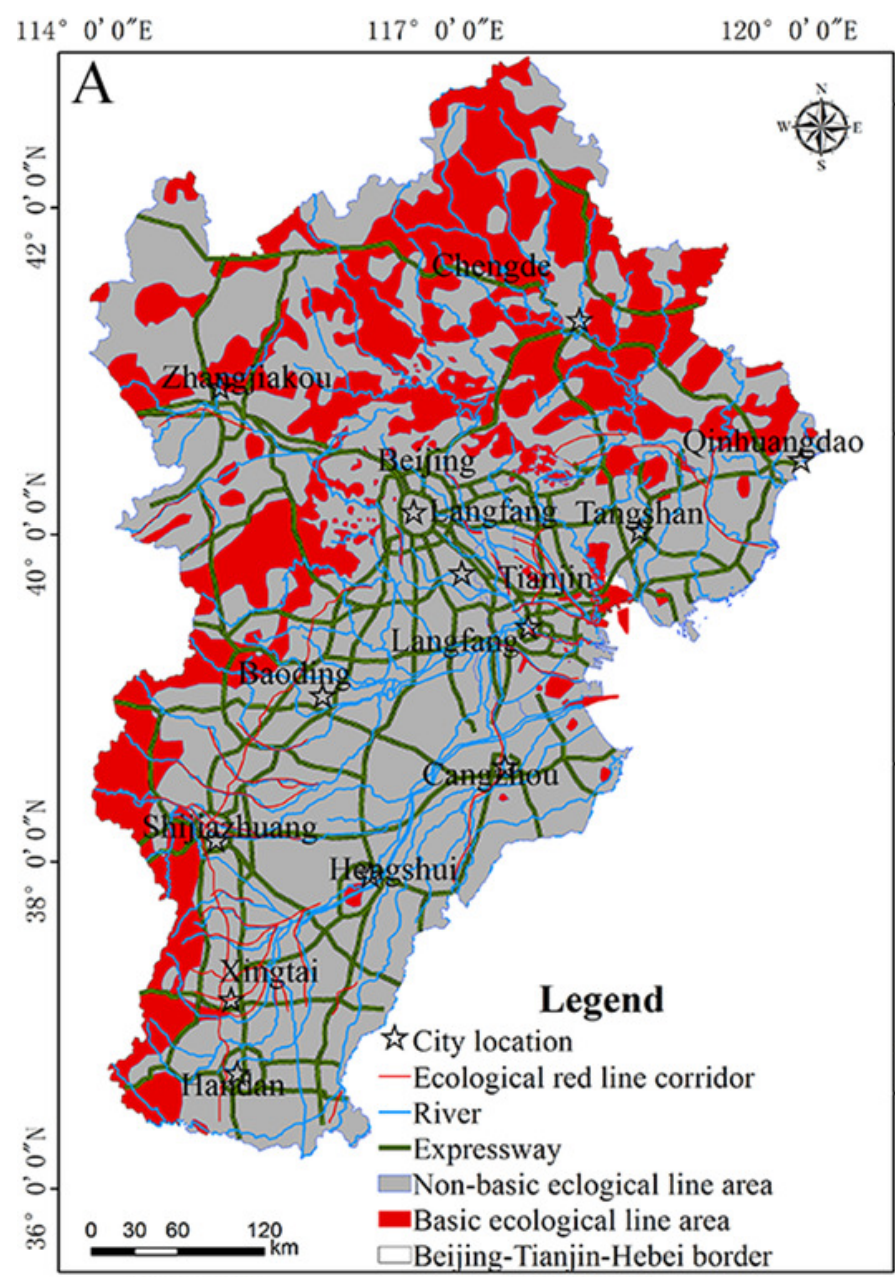

$114^{\circ} 0^{\prime} 0^{\prime \prime} \mathrm{E} \quad 117^{\circ} 0^{\prime} 0^{\prime \prime} \mathrm{E}$

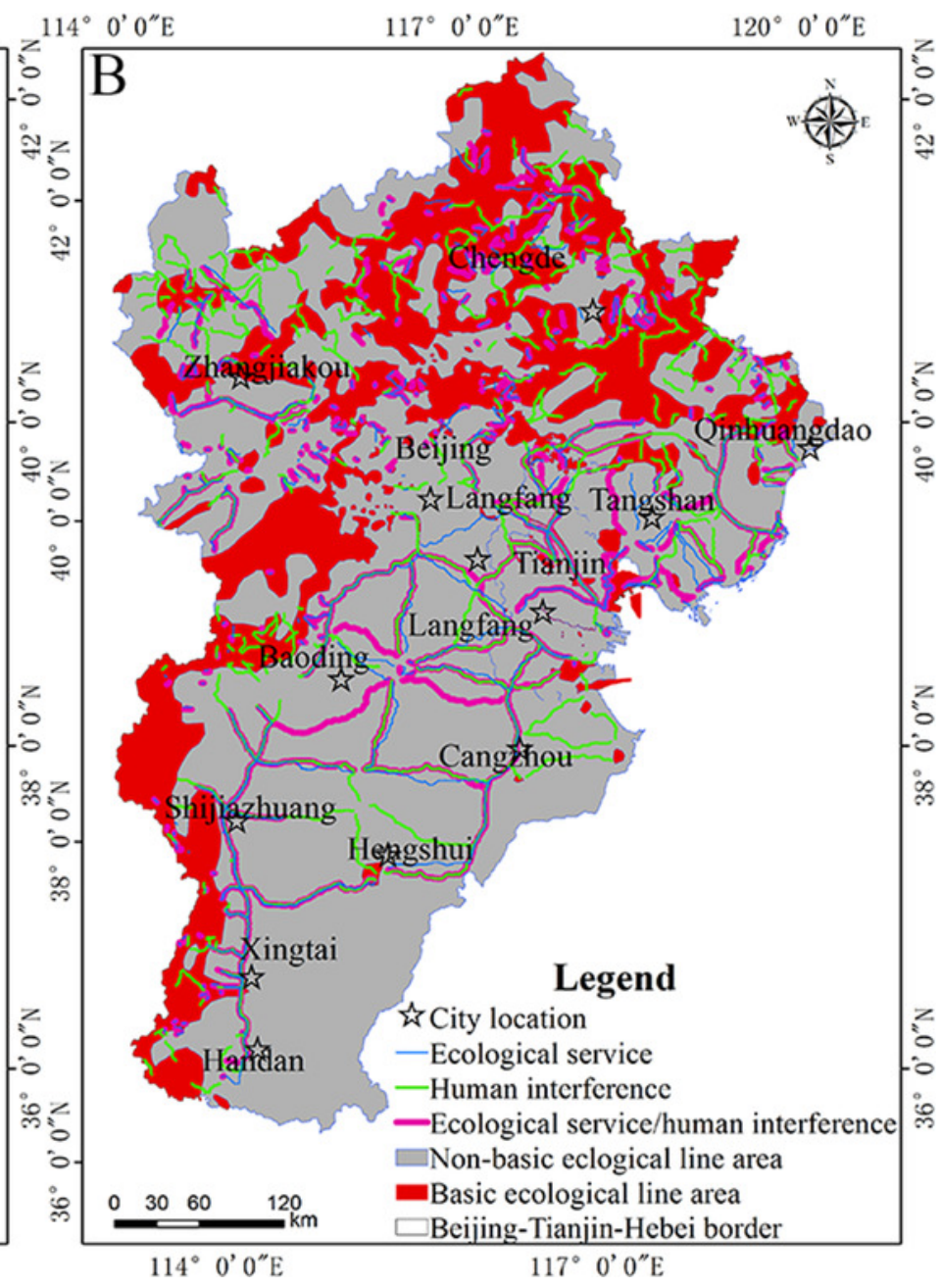




\section{Figure 7}

Comparison of ecological corridors.

(A) spatial pattern of human disturbance and ecological red line corridors; (B) ecological service and ecological red line corridors; (C) human disturbance and ecological services and ecological red line corridors; (D) human disturbance and river; (E) ecological service and river; (F) human disturbance and ecological services and river; (G) human disturbance and expressway; (H) ecological service and expressway; (I) human disturbance and ecological services and expressway. Mapping of how the current corridor of the Beijing-Tianjin-Hebei urban agglomeration coincides with: (J) human disturbance corridor; (K) ecological services corridor; (L) human disturbance and ecological services corridor. 

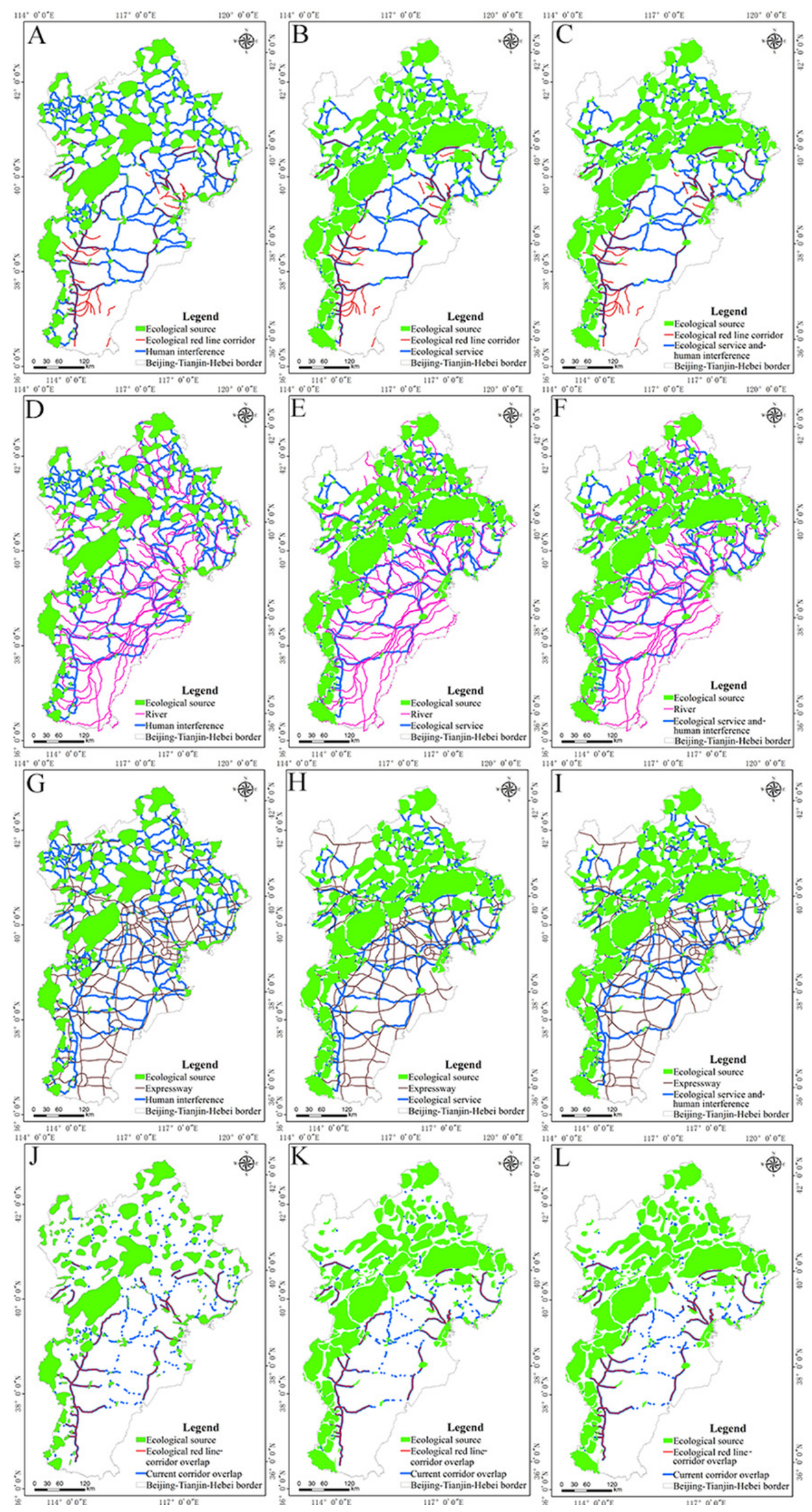

PeerJ reviewing PDF | (2019:03:35477:2:1:NEW 13 Jun 2019) 